Spatial Processing in the Electrosensory System

\title{
Behavioral and neural aspects of the spatial processing of conspecifics in the electrosensory system
}

\author{
Oak E Milam, Keshav L Ramachandra and Gary Marsat \\ Biology Department, West Virginia University
}

Corresponding author:

Gary Marsat

Gary.marsat@mail.wvu.edu

53 Campus Dr,

WVU Biology Dept,

Morgantown, WV, 26506

Acknowledgements: We thank Len Maler, Andrew Dacks and Frederico Predaja for helpful comments on the manuscript. 
Spatial Processing in the Electrosensory System

\begin{abstract}
Localizing the source of a signal is often as important as deciphering the signal's message. Localization mechanisms must cope with the challenges of representing the spatial information of weak, noisy signals. Comparing these strategies across modalities and model systems allows a broader understanding of the general principles shaping spatial processing. In this review we focus on the electrosensory system of knifefish and provide an overview of our current understanding of spatial processing in this system, in particular, localization of conspecific signals. We argue that many mechanisms observed in other sensory systems, such as the visual or auditory systems, have comparable implementations in the electrosensory system. Our review therefore describes a field of research with unique opportunities to provide new insights into the principles underlying spatial processing.

Keywords: spatial information; localization of conspecifics; neural mechanisms; sensory processing; sensing behavior.
\end{abstract}


Spatial Processing in the Electrosensory System

\section{Introduction}

The role of sensory systems is to capture information about the environment and although much of the behaviorally relevant information is contained in the quality and quantity of a signal, its spatial structure is also relevant (Bradbury \& Vehrencamp, 2011; McGregor, 1993).

Communication and conspecific signals carry much of their meaning in their spectral and temporal modulation: amplitude and frequency modulations in bird songs (Konishi, 1985; Lohr, Wright, \& Dooling, 2003 Reid et al., 2005), colors of body ornaments (Doucet, Mennill, \& Hill, 2007; Guilford \& Dawkins, 1993; Keyser \& Hill, 2000), or chirping patterns in weakly electric fish (Dunlap, DiBenedictis, \& Banever, 2010; Engler, Fogarty, Banks, \& Zupanc, 2000). Even for olfactory signals, the message is represented by the quality (i.e. odor identity) and quantity of the odor (Aragón, 2009; Daly et al., 2016; de Bruyne \& Baker, 2008). In most -if not all- cases, the receiver also tries to determine the location of the signal's source. Seeking out a signaling mate (Arikawa, Wakakuwa, Qiu, Kurasawa, \& Stavenga, 2005; Byrne \& Keogh, 2007; Mathis, 1990), localizing threats and the alarm calls they trigger in conspecifics (Cäsar, Zuberbühler, Young, \& Byrne, 2013) or avoiding a competitor broadcasting its territorial claim (Bee, 2000; Behr, Knörnschild, \& Von Helversen, 2009) are a few examples where the spatial aspect of the signal is key in guiding the behavior successfully. Signal localization is faced with important challenges as a signal's directionality and strength can be weakened as it propagates through the environment (Bradbury \& Vehrencamp, 2011). Decades of research on the neural and behavioral mechanisms underlying signal localization in various modalities and model systems have led to rich insight into how these challenges are met. As always, comparing solutions across modalities and species can reveal core principles of a mechanism and key adaptation permitting new functions. The study of sensory processing in weakly electric fish has provided important contributions to this comparative approach to understanding neural processing. An extensive literature on the temporal processing of electrosensory signals is matched by a relatively smaller but growing literature focused on the spatial aspects of communication signals. We provide in this review an overview of our current knowledge on the spatial processing of electrocommunication signals but most importantly we point out key challenges faced by this system and commonalities with other sensory systems. We argue that that the difficulty in 
Spatial Processing in the Electrosensory System

localizing weak signals, signals in noise, or simply localizing accurately requires sensitive and efficient mechanisms that share many resemblances across modalities.

\section{The electrosensory system}

The ability to sense electric fields is thought to have evolved early in the vertebrate lineage (Bodznick \& Northcutt, 1981) and is developmentally derived from lateral line placodes (Modrell, Bemis, Northcutt, Davis, \& Baker, 2011). Electroreception was lost in teleost fish but regained at least twice (in Osteoglossomorpha and Ostariophysi) thereby explaining the presence of electroreceptors in a variety of species, including catfish, elephantnose fish and knifefish (see Baker, Modrell, \& Gillis, 2013 for a recent review on the topic). In teleosts, electroreceptors are thought to have evolved as a modification of neuromast (Baker et al., 2013). Beyond their detailed evolutionary trajectory, electroreceptor origin is clearly linked to the lateral line and mechanosensory system, similar to the origin of vertebrate auditory receptors (Duncan \& Fritzsch, 2012). As a reflection of their similar evolutionary origin, both electroreceptors and auditory receptors travel along the VIIIth cranial nerve (Carr, Maler, \& Sas, 1982). Ampullary receptors are the most common type of electroreceptors across species, but in two orders of teleost (Gymnotiformes and Mormyriformes) a second type of electroreceptor evolved - tuberous receptors (Szabo, 1974). Where ampullary receptors are sensitive to low-frequency electric signals, such as the ones produced by contracting muscles, tuberous receptors are sensitive to high frequencies (Bennett, Sandri, \& Akert, 1989; Hopkins, 1976; Maler, 2009a; Maler, 2009b) and their evolution accompanies the evolution of electric organs (EO) that generate highfrequency weak electric fields (Fig 1). Derived from a modified muscle or a modified nerve terminal, EO produce pulsatile or continuously oscillating electric fields (Kramer, 1996). Weakly electric fish (Gymnotiformes and Mormyriformes) thereby possess an active electrosense where the electric organ discharges (EOD) (Lissmann, 1958) are perceived by electroreceptors on the skin. Anything in their environment that is more or less resistive than water will cause a distortion of this electric field that will cast an "electric shadow" on the sensory surface (Rasnow, 1996). They rely heavily on this active sense to navigate, localize prey, but also to communicate and interact with conspecifics (Bullock, Hopkins, Popper, \& Fay, 1986; Lissmann, 1963). Although Gymnotiformes and Mormyriformes have many similarities in the way they use and process electric signals, the fact that they evolved this active electric sense independently also leads to significant differences, in particular at the neural level. To facilitate the discussion 
Spatial Processing in the Electrosensory System

in this review, we will focus on knifefish (Gymnotiformes), and more specifically the wave type species (e.g. glass knifefish or ghost knifefish) that produce continuous EODs rather than pulsed EODs (Bass 1986; Bennett, 1971); we will simply refer to them as weakly electric fish.

Knifefish are typically nocturnal species and thus rely heavily on this active electrosense to perceive their environment. The sensory image caused by objects close to them is quite accurate thanks to a relatively high density of receptors over the entire surface of the skin (Carr et al., 1982); allowing them to be efficient hunters of invertebrate prey (Nelson \& MacIver, 1999). Similarly, they can locate and identify a conspecific based on the EOD it produces or mediate social interactions via electrocommunication signals such as chirps (Engler \& Zupanc, 2001). The sensitivity of their ability to locate each other based on this sense is easily observable both in the field or in the lab (see below). For example, they will chase each other at high speed in a noisy environment with multiple other signal sources or locate each other at such distances that they must base this detection on extremely weak signals.

\section{Localization of conspecifics}

The localization of conspecific signals is a different sensory problem to the localization of small objects such as prey items. An object close to the body will cause a local disturbance in the EOD which will be picked up by a limited number of receptors on the corresponding portion of the skin (Rasnow, 1996). The localization strategy in this case is closer to visual localization or localization in the somatosensory system where exclusive activation of a subset of receptors encodes location in a labeled line code (Cichy \& Teng, 2017; Hartmann \& Bower, 2001; Krekelberg, Kubischik, Hoffmann, \& Bremmer, 2003; Okada \& Toh, 2006). Localizing a conspecific based on the EOD it produces cannot rely on this strategy since the sender's EOD will impact the majority of electroreceptors over the entire skin surface (Kelly, Babineau, Longtin, \& Lewis, 2008). Localization must therefore rely on comparison of the input at the various receptors and location be computed by the nervous system based on the differences. This task shares similarities with localization in the auditory system, which relies on comparisons of binaural input (Brand, Behrend, Marquardt, McAlpine, \& Grothe, 2002; Carr \& Konishi, 1990; Jeffress, 1948). Localization in the electrosensory system might therefore be described as a hybrid mechanism that relies on a labeled line strategy for passive objects (e.g. small prey) that cause a local electrical disturbance, but needs to compute the spatial information about active 


\section{Spatial Processing in the Electrosensory System}

electro-generating sources (e.g. conspecifics). As such, the electrosensory system is faced with many of the same challenges faced by the auditory or the visual system when localizing signal sources in complex environments. Whether it is a question of localization accuracy (e.g. auditory system), localizing in a noisy environment (cocktail party problem in the auditory system) (Cherry, 1953; Liberman, Harris, Hoffman, \& Griffith, 1957) or foreground-background separation (visual system) (Ölveczky, Baccus, \& Meister, 2003), there is a rich literature documenting the various neural and behavioral mechanisms in place to face these challenges.

The electrosensory system has a long history of contribution to our understanding of sensory processing. Issues of temporal coding have been particularly well explored in this system (Gabbiani, Metzner, Wessel, \& Koch, 1996; Krahe, Bastian, \& Chacron, 2008). Understanding localization in the electrosensory system has focused heavily on the spatial aspect of prey capture or the localization of small objects (Babineau, Lewis, \& Longtin, 2007; Caputi \& Budelli, 2006; Nelson \& MacIver, 1999; Rasnow, 1996). Less is known about the spatial processing of conspecific signals, but there are several new studies and a growing interest in the topic (Kelly et al., 2008). Our goal in this review is to provide an overview of what is known about localization of conspecific signals in weakly electric fish, pointing out along the way how this model system can contribute to our general understanding of sensory processing. We will first discuss the behavioral aspects of conspecific localization to provide a good understanding of the tasks that must be carried out by the nervous system. We will then describe the neural mechanisms underlying spatial processing and point out the issues that remain poorly understood. Finally, we compare the electrosensory system with other modalities to highlight the common challenges they face and discuss the similarities and differences in how they accomplish these tasks.

\section{Behavior and signal}

This electrosense is advantageous for navigating at night or in murky waters and these are two challenges faced by knifefish. Their ability to navigate and locate prey based on this sense is well documented (Nelson \& MacIver, 1999; Postlethwaite, Psemeneki, Selimkhanov, Silber, \& MacIver, 2009; Stamper, Roth, Cowan, \& Fortune, 2012; Von Der Emde, Schwarz, Gomez, Budelli, \& Grant, 1998). Similarly, they also rely heavily on this electrosense when interacting with conspecifics to identify, communicate and locate each other. Identity can be determined 
Spatial Processing in the Electrosensory System

from the EOD pattern (Fig 2a): depending on the species, EOD frequency, shape or pulse pattern can be used to identify conspecifics from individuals of another species (Zupanc et al., 2006) or even differentiate amongst conspecifics (Zakon, Oestreich, Tallarovic, \& Triefenbach, 2002). In wave type species, the EOD frequency (and possibly shape; Kolodziejski, Sanford, \& Smith, 2007; Petzold, Marsat, \& Smith, 2016) is perceived indirectly. Indeed, when two or more individuals come into close proximity, the electric fields of each fish summate, and the resulting field contains amplitude and phase modulations, collectively known as a "beat" (Fig 2b; Heiligenberg, 1991). The beat frequency is equal to the frequency difference between the EOD of the sender and receiver (note that both fish send and both fish receive but we use this terminology throughout this article to describe the perspective we use (Stamper, Madhav, Cowan, \& Fortune, 2012). Furthermore, phase modulations can indicate whether the other fish has an EOD frequency higher or lower than its own (see Carlson \& Kawasaki, 2007; Metzner, 1999; Stamper et al., 2012 for more information). Determining beat frequency is important since each fish has a baseline EOD frequency and thus individual discrimination can be based on this signal. In some species, EOD frequency is sexually dimorphic leading beat frequencies to be lower during same-sex interactions and higher for male-female pairs (Engler \& Zupanc, 2001). Since beat frequency can indicate species, sex, maturity and even individual identity, many species react differently when exposed to beat signals of various frequencies. For example, the rate of production of certain communication signals in black ghost or brown ghost knifefish depends on the beat frequency (Hupé, Lewis, \& Benda, 2008). The most common type of communication signal produced by these fish -chirps- are brief increases in EOD frequency (see Kolodziejski et al., 2007 for more info).

\section{$\underline{\text { Sensitivity of conspecific detection and localization }}$}

In wave type fish, since the beat is the modulation of the fish's own EOD as a result of the presence of a second fish, it carries information about the sender's location. The beat signal will strengthen as the conspecific gets closer and the strength of the signal across the sensory surface (i.e. the body's surface) correlates with its relative position. Both lab and field studies clearly show that they monitor this information to detect the presence and position of a conspecific. In an insightful field study, Henninger et al (Henninger, Krahe, Kirschbaum, Grewe, $\&$ Benda, 2018) used grids of electrodes placed in river streams and creeks to triangulate and follow individuals in their natural environment during long periods of time. Besides revealing the 
Spatial Processing in the Electrosensory System

behavioral and communication dynamic happening during various types of interactions including courtship or aggression- this study showed the range of detection of conspecifics via this electrosense. Although their data suggests that fish routinely communicate with each other over distances of up to $30 \mathrm{~cm}$, it also shows that two fish can detect and assess a conspecific at distances of 1 meter or more. For example, they showed that a resident fish-initiated attacks on an intruder located as far as $1.7 \mathrm{~m}$ away. To emphasize how challenging this task is, they estimated the strength of the sender's signal and showed that a fish $30 \mathrm{~cm}$ away creates a signal of $10 \mu \mathrm{V} / \mathrm{cm}$ and that a fish $1.7 \mathrm{~m}$ away causes a signal smaller than $1 \mu \mathrm{V} / \mathrm{cm}$. Note also that this data suggests that these weak signals were not only detected, but also localized since it guided the resident to launch an attack directed at the intruder.

Laboratory studies confirm the sensitivity of this system in detecting and locating a conspecific. Fish adjusted their EOD output (i.e. the response called "envelope tracking") when presented with beats of 10-15\% contrast (Metzen, Huang, \& Chacron, 2018) which would correspond to a conspecific 20-30 cm away (Fotowat, Harrison, \& Krahe, 2013). In another study, fish exposed to a conspecific signal presented from various distances regularly produced chirps only in response to the stimuli located fairly closely $(10 \mathrm{~cm})$ (Zupanc et al., 2006). However, conditioned responses to weak signals demonstrated that fish could detect signals weaker than $1 \mu \mathrm{V} / \mathrm{cm}$ corresponding to a distance of up to $1.6 \mathrm{~m}$ (Knudsen, 1974; Knudsen, 1975). Therefore, despite coming to their conclusion through very different methods, the field and laboratory studies provide very similar estimates and identify a certain range within which fish actively interact with each other (e.g. chirp or envelope tracking) and a wider range delineating the limits of their detection and localization ability.

\section{Conspecific localization and EOD temporal modulation}

Information about conspecific location is present in two aspects of the signal: its temporal modulations and its spatial structure (see next section). Temporal modulations are indeed imparted by the relative movement of two fish. As a sender moves closer and further from the receiver, the beat will proportionally increase and decrease in strength (Fig 2c). The strength of the beat is also called its "contrast" and contrast modulations are called the "envelope signal". The characteristics of these envelope signals have been determined experimentally by recording the signals received by a fish exposed to one or several other moving conspecifics (Fotowat et 


\section{Spatial Processing in the Electrosensory System}

al., 2013; Yu, Hupé, Garfinkle, Lewis, \& Longtin, 2012). Since movement is relatively slow, envelope signals are typically low frequency $(<10 \mathrm{~Hz})$. The data also confirmed that the beat elicited by a conspecific nearby can be strong (often above $50 \%$ contrast at $<10 \mathrm{~cm}$ ), but decreases quickly with distance (a few \% at $30 \mathrm{~cm}$; Fotowat et al., 2013) since these electric fields decrease in strength as a function of the cube of the distance (Angel A. Caputi, Aguilera, Carolina Pereira, \& Rodríguez-Cattáneo, 2013). Furthermore, these recordings illustrate another important principle that influences the properties of electric signals. The strength of the signal is not simply related to the distance but also to the relative orientation of the receiver and sender “dipoles” (Rasnow, Assad, \& Bower, 1993). Since voltage is a difference in potential between two points ( 2 poles), the EO is a stimulus dipole and electroreceptors are sensing dipoles detecting the potential difference across the skin. Electric fields are thus characterized by isopotential lines and a sensing dipole positioned parallel to an isopotential line would not pick up the signal even if it is close to the stimulus dipole (Fig 1) (Assad \& Bower, 1997; Rasnow et al., 1993). Consequently, the strength of the envelope can decrease to zero as the fish moves away or as it rotates $90^{\circ}$ making the envelope signal picked up by a given receptor ambiguously related to the location of the sender.

Envelope signals are common in various modalities. In the visual system they are linked to the ability to distinguish contrast based visual contours (Grosof, Shapley, \& Hawken, 1993). They are also used by the auditory system for speech perception and sound localization (Lohuis \& Fuzessery, 2000; Smith, Delgutte, \& Oxenham, 2002). The electrosensory system has provided important insight into how these signals are processed by the nervous system (see next section), but we do not yet know how they are used to gage the distance of the sender. Furthermore, azimuth and elevation of the sender relative to the receiver is not encoded in this temporal signal, it can only be estimated by comparing the strength of the signal across the sensory surface.

\section{Electrosensory image}

The sensory surface is well suited to capture the spatial aspect of the sensory environment. Most of the body surface of knifefish contains a high density of electroreceptors each capturing the electrical potential within its vicinity (Carr, Maler, \& Sas, 1982). Distortion of the fish's own EOD caused by its environment can thus be mapped on this spatially organized 


\section{Spatial Processing in the Electrosensory System}

sensory array. Distortions experienced by these fish can be categorized as either a passive electric image or an active electric image. The active electric image arises when an object or animal that is more or less conductive than the surrounding water locally influences the strength of the electric field generated by the fish. For example, a conductive prey item near the head (Fig 3) will locally increase the strength of the electric field and cast an "electrical shadow" (or a bright spot in this case) on the skin. A series of seminal studies using modeling, physiological and behavioral approaches have detailed the characterization of the electrosensory image of prey items during hunting behaviors (Nelson \& MacIver, 1999; Nelson, MacIver, \& Coombs, 2002). The authors measured the 3D relative position of the fish and its prey, modeled the electrosensory image that would result, estimated the activation strength of the various receptors and reconstructed a 3D activation map of the sensory surface. They determined that black ghost knifefish typically detect prey when they are 1-2 cm away that elicit a signal of 1-3 $\mu \mathrm{V}$ and can potentially detect a signal as weak as $0.2 \mu \mathrm{V}$. These studies point out once again the extreme sensitivity of this system and provide a clear understanding of how these signals are represented at the periphery. The neural mechanisms underlying prey localization and detection are also a good example of sophisticated neural processing strategies used to accomplish challenging tasks (see next section) (Chacron \& Bastian, 2008; Clarke, Longtin, \& Maler, 2014; Jung, Longtin, \& Maler, 2016). A conspecific in close proximity to the receiver will also cast such an active electrosensory image -albeit a bigger one- but few studies have characterized this sensory image. In a recent study combining behavioral recordings and modelling of the electric field and sensory image, Pedraja et al (2016) showed that this active image could guide behavior during aggressive encounters. However, they showed that the passive electrosensory image (see below), rather than the active one, was better correlated with the initiation of attack behavior at close range. This study also indicates that the image of the conspecific is fairly sharp at close range (a small portion of receptors are strongly activated and the others much more weakly) thereby giving a clear labeled-line representation of conspecific location. In contrast, the image elicited by a conspecific further away $(>10 \mathrm{~cm})$ is uniformly weak, thus detection most likely involves pooling all the responses together to average out the noise and localization must rely on comparing the weak responses to determine the even-weaker differences among them. This analysis highlights once again the challenging task that this system must perform. Although it is still not clear to what degree they rely on the passive image versus a combination of passive and 
Spatial Processing in the Electrosensory System

active images in close range interactions, the active image cannot underlie the ability to detect and localize conspecifics far away (Knudsen, 1975).

They must thus rely on the passive electrosensory image to detect and localize distant conspecifics. The passive image consists of the spatial pattern of distortion of the receiver EOD caused by the sender EOD. It is important to point out that this terminology, although well defined for prey and for pulse species, is more ambiguous for wave-type species since this passive image is the result of both sender and receiver's active signals (EODs and the resulting beat). Furthermore, the passive and active components will both be perceived through modulations of the receiver's own EOD and thus, are not truly different images but different components of the electrosensory image. We nevertheless use this terminology for consistency with previous studies (e.g. Pedraja, Perrone, Silva, \& Budelli, 2016).

The strength of the beat signal at different points on the receiver's skin will vary with position and orientation of the sender. A sender located in front, for example, would cause stronger beats on the rostral than caudal end of the receiver. The detailed activation pattern of the sensory surface also depends on receptor orientation (e.g. dorsal receptors are nearly orthogonal to the nearby receptors on the side of the body). Several researchers have modelled the electrosensory image caused by a conspecific either fixed (Kelly, Babineau, Longtin, \& Lewis, 2008) or approaching (Castelló, Aguilera, Trujillo-Cenóz, \& Caputi, 2016; Gómez-Sena, Pedraja, Sanguinetti-Scheck, \& Budelli, 2014) the focal fish. Despite being extremely valuable data, the studies were limited to a $2 \mathrm{D}$ plane and the sensory surface was represented as a linear array of receptors with the same orientation. Considering how receptor activation will depend on the relative orientation, in $3 \mathrm{D}$, of the receptor relative to the stimulus, further studies are required to obtain a detailed characterization of the sensory image of conspecifics. An incomplete understanding of the spatial structure of these sensory signals limits our ability to understand how the sensory system extracts this spatial information. Nevertheless, a rich literature on sensory processing in this system documents many of the neural processes relevant to this task. 
Spatial Processing in the Electrosensory System

\section{Sensory system and neural processing}

\section{Introduction}

Representation of space in sensory systems, for example through topographic mapping, is a key feature in most modalities. In the electrosensory system, the sensory images activate electroreceptors distributed everywhere across the skin. Ampullary receptors (mediating lowfrequency passive electrosensation; see Introduction) are less numerous ( 700 total in brown ghost knifefish) compared to tuberous receptors ( 13,000-17,000 total; Carr et al., 1982). The density of ampullary and tuberous receptors varies across the body surface. Regions of the mouth, face, and head are higher in receptor density, resulting in the formation of an electrosensory fovea. Similar to other sensory systems, this foveal arrangement of receptors permits a higher resolution of sensory input and its location near the mouth is well suited to guide the final stages of prey capture.

There are two kinds of tuberous receptors involved in active electrosensation: T-units and P-units. Time coding units (T-units) are few in number and form a separate channel early in the sensory pathway through spherical cells of the electrosensory lateral line lobe (ELL) and onto a dedicated layer of the Torus semicircularis (Ts) (Maler, Sas, \& Rogers, 1981). Most tuberous receptors are amplitude coding (or probability coding units: P-units), providing direct input to ELL pyramidal cells. P-units are solely responsible for encoding the amplitude of the fish's own EOD and the amplitude modulations (AMs) arising from electrolocation and electrocommunication (Nelson, Xu, \& Payne, 1997). All tuberous receptors split three ways providing trifurcated input unilaterally to the centromedial segment (CMS), centrolateral segment (CLS), and the lateral segment (LS), whereas ampullary receptors project exclusively to the medial segment (MS) of the ELL (Heiligenberg \& Dye, 1982). Pyramidal cells across the different maps and different layers of the ELL (deep, intermediate or superficial) vary in their response properties (e.g. low-pass to high pass) or receptive field size and polarity (ON-center or OFF-center cells) (Krahe, Bastian, \& Chacron, 2008; Saunders \& Bastian, 1984). The three tuberous-driven maps thus have properties adapted for processing different signals. For example, CMS is crucially involved in the jamming avoidance response (JAR), certain stages of prey capture might rely more heavily on CLS, while LS is best at encoding communication signals (Maler, 2009b ; Marsat, Proville, \& Maler, 2009; Metzner \& Juranek, 1997). ELL neurons 


\section{Spatial Processing in the Electrosensory System}

project to the Ts in the midbrain and to areas providing feedback to the ELL (see below). Ts has a laminar organization and a complex network of inputs, outputs and connections between layers. Electrosensory input to the Ts is somatotopically conserved and restricted specifically to the dorsal Ts (Carr et al, 1981). The dorsal Ts is divided into twelve laminae, of which layers 3, $5,6,7,8 \mathrm{~b}$, and $8 \mathrm{~d}$ receive electrosensory input. Cells that respond to communication stimuli likely lie within the deeper layers of the Ts. At higher levels the electrosensory pathway splits as Ts projects to the optic tectum (TeO) involved in spatial processing, to the nucleus electrosensorius ( $\mathrm{nE}$ ) processing communication signals, and the preglomerular nucleus (PG) that mediates connectivity with the forebrain (Fig 4) (Giassi, Ellis, \& Maler, 2012; Zupanc \& Horschke, 1997). As expected, extensive feedback from forebrain areas but also from mid and hindbrain areas interconnect these regions; most are not discussed further here (Bell \& Maler, 2005; Giassi et al., 2012).

The processing of conspecific signals has been most extensively studied at the receptor and ELL levels and so we focus on the early sensory processing in the next sections of this review. Conspecific stimuli cause both phase and amplitude modulations in the input signal (Stamper, Fortune, \& Chacron, 2013; Stamper et al., 2012; Yu et al., 2012). While phase information relayed by the T-unit receptors is essential to generate the JAR behavioral response, the bulk of the processing at this early stage focuses on the AM. Most notably, the beat AM present during conspecific interactions must be detected, localized and its frequency determined. As is typical with early stages of sensory processing, receptors encode the AM fairly linearly and ELL pyramidal cells -although possessing important non-linearities- still represent the shape of a broad range of AM signals in modulations of their firing rate. Various response properties and coding mechanisms have been described at this level such as interspike interval (ISI) correlations to reduce noise (Ratnam \& Nelson, 2000), bursting to improve feature detection (Gabbiani, Metzner, Wessel, \& Koch, 1996) or decorrelation to enhance information bandwidth and coding accuracy (Marsat \& Maler, 2010). We also have a detailed understanding of how communication signals, chirps more specifically, are encoded in the early sensory pathway. Chirp coding crucially depends on the frequency of the beat that is present in the background of these interactions (Marsat, Longtin, \& Maler, 2012; Walz, Grewe, \& Benda, 2014). For example, the receptors can synchronize or de-synchronize in response to a chirp depending on whether the beat is low or high frequency (Benda, Longtin, \& Maler, 2006) and ELL neurons might respond 
Spatial Processing in the Electrosensory System

with bursts only for some chirp-beat combinations (Allen \& Marsat, 2018; Benda et al., 2006). For both chirp and beat coding, Ts neurons respond more sparsely and selectively (Vonderschen \& Chacron, 2011) although some neurons still encode the signal AM in detail. Although the coding properties alluded to above could influence the conspecific localization mechanism, we will focus below on two mechanisms that play a large role in this process, namely envelope coding and beat cancellation.

We described in the behavior section how the movements of interacting fish would cause an envelope modulation - a signal that could serve to gage distance between individuals. Several recent publications have clarified the neural mechanisms underlying envelope coding (Huang, Metzen, \& Chacron, 2018; Metzen \& Chacron, 2014; Savard, Krahe, \& Chacron, 2011; Thomas, Metzen, \& Chacron, 2018). For firing rate to reflect the envelope strength, a non-linear transformation must happen. To illustrate this point, consider an envelope signal that decreases as if the conspecific was moving away. During this decrease in envelope (beat contrast), the mean EOD strength that reaches the receptors does not change, it still varies around the same amplitude of the fish's own EOD. Therefore, if mean firing rate is to change, even though mean EOD strength does not change, the nervous system must implement a non-linear transformation. Several mechanisms might contribute to the envelope coding mechanism. At weaker intensities, ovoid cells can perform this task (Middleton, Longtin, Benda, \& Maler, 2006) and direct feedback can enhance the sensitivity of the envelope responses (Huang et al., 2018). At higher intensities, the receptors provide the main mechanism implementing this non-linear transformation. Due to the threshold and saturation of receptors, the incoming signal is halfrectified and then low-pass filtered at the synapse with the pyramidal cells (Savard et al., 2011). These mechanisms extracting the envelope strength could therefore contribute to evaluating conspecific distance.

The ELL receives both direct feedback from the nucleus praeminentialis (nP; see Figs 4, 5) and indirect feedback from cerebellar granular cells (EGp, Figs 4, 5). The encoding of beats in the ELL is also influenced by indirect feedback inputs (Bastian, 1986a; Bastian, 1986b). The role of the latter in cancelling the response to beats has been extensively documented (Bol, Marsat, Harvey-Girard, Longtin, \& Maler, 2011; Chacron, Doiron, Maler, Longtin, \& Bastian, 2003). A subset of pyramidal cells, the superficial and to some degree the intermediate cells, 
Spatial Processing in the Electrosensory System

receive massive parallel fibers inputs onto their apical dendrites. Plasticity at these synapses adjusts the relative contribution of each fiber so that the overall input is in antiphase to the feedforward input from the receptors thereby reducing the strength of the response in these cells (Bol et al., 2011; Harvey-Girard, Lewis, \& Maler, 2010). This mechanism operates for relatively low frequency beats but does not cancel the responses to beat frequencies higher than $15-20 \mathrm{~Hz}$ (Chacron, Maler, \& Bastian, 2005). This feedback only affects a subset of cells; it does not influence the response of deep pyramidal cells and cancellation in the CMS and LS segments is less pronounced. Nevertheless, since it affects the coding of the beat, and because beat strength can mediate the localization of conspecifics, this feedback can potentially influence the localization mechanism (see below).

\section{Topographic representation and spatial information}

Each receptor on the skin captures the strength of the electric signal at a given point on the skin and thus the pattern of activation of the array of electroreceptors covering the body will reflect the spatial structure of the electrosensory image elicited by the presence of a conspecific. This spatial pattern of activation of receptors is conserved through the topographic projection into the ELL. Thereby each of the four segments of the ELL (from medial to lateral) is organized as a topographic map of the sensory surface (Lannoo, Maler, \& Tinner, 1989). The three maps sensitive to EOD (CMS, CLS and LS) differ in size and in the shape of their topographic representation (see Krahe \& Maler, 2014). CMS is the largest map containing 2800 pyramidal cells (in brown ghost knifefish) and the head representation is disproportionately big compare to the trunk. At the other extreme, LS is the smallest segment ( 900 pyramidal cells on each side) and the head representation occupies a smaller portion of the maps compared to CMS. Pyramidal cells are organized in columnar functional units where three ON cells and three OFF cells located at various depths (deep, superficial or intermediate) have receptive fields (RFs) with similar centers. Each of the six pyramidal cells within a column has different response properties and connectivity thus representing complementary channels of information. Taking digital images as an illustration, each column would represent a pixel and the spatial resolution of the sensory image on one side of the body would thus be of 150, 235 or 470 columns for LS, CLS and CMS segments respectively (Maler, 2009b). 


\section{Spatial Processing in the Electrosensory System}

As suggested by the anatomy, the RFs of ELL cells vary from segment to segment with smaller RFs in CMS (6-14 $\mathrm{mm}^{2}$ corresponding to the area covered by 25-50 P-units), than CLS (26-60 mm²/100-240 P-units), and much larger RFs in LS (160-360 m²/640-1400 P-units; (Bastian, Chacron, \& Maler, 2002; Shumway, 1989a; Shumway, 1989b). The segments also vary in amount of overlap between the RF of neighboring cells (larger in LS than CMS). Pyramidal cells have a classical center receptive field and a surround receptive field with an ONcenter/OFF-surround (or vice versa) pattern similar to the well-known phenomenon in the visual system. The size of the surround relative to the center also varies across maps with LS maps having proportionally smaller surrounds and CMS having larger surrounds.

These differences in feedforward convergence and RF sizes lead to obvious differences in spatial representation and sensitivity. The small RFs are associated with high spatial resolution but lower sensitivity and might thus be geared towards detecting nearby small objects such as prey. Larger RFs lead to lower spatial resolution but higher sensitivity since the input from many receptors are pooled and the noise can be averaged out. They would be best at responding to weak, distant signals that cast spatially extended (diffuse) images such as a distant conspecific. Spatial mapping in the ELL is thus organized to efficiently process spatial information from a variety of signals.

The topographic representation is preserved in the Ts where many of the layers contain a map of the body surface (Carr, Maler, Heiligenberg, \& Sas, 1981). Similarly, the tectum is topographically organized but the other targets of Ts (nE and PG) are not (Fig 4). In nonelectrosensory fish species, the tectum is largely driven by visual inputs and directs visually guided behaviors. It is thus no surprise that this structure receives electrosensory inputs in species that rely heavily on this sense to guide motor behavior. While the tectum projects to locomotive motor areas, the $\mathrm{nE}$ projects to electromotor areas to control EOD and communication signal generation. Note that $\mathrm{nE}$ and tectum are interconnected through feedback loops therefore; a communication signal from a conspecific processed in $\mathrm{nE}$ can influence the spatial processing of the conspecific location in tectum or the spatially directed behavior it generates.

Although spatial representation and coding of an active conspecific signal has not been investigated at any level of the nervous system, spatial coding of passive objects has been the 
Spatial Processing in the Electrosensory System

focus of several behavioral and neurophysiological studies (e.g. Caputi \& Budelli, 2006; Nelson \& MacIver, 1999; Sicardi et al., 2000). The electrosensory image of a daphnia at the time of detection can be as weak as $0.2 \mu \mathrm{V}$ and covers a small (2-3 cm diameter) diffuse area of the body surface (Chen, House, Krahe, \& Nelson, 2005). This very weak signal barely causes any increase in the firing rate of electroreceptors or ELL pyramidal cells and researchers have investigated the mechanism that permits such a sensitive detection. For example, it was suggested that a $0.2 \mu \mathrm{V}$ prey signal would elicit an increase in firing rate of 0.2 spikes corresponding to about $1 / 10^{\text {th }}$ the $\mathrm{SD}$ of baseline firing rate (i.e. noise). The most obvious way to solve this problem is to pool and average the information over many receptors. Theoretical calculations based on the strength and size of these signals and the convergence of electroreceptors onto pyramidal cells of various maps determined that, given certain assumptions, the LS could achieve reliable detection of 0.2 $\mu \mathrm{V}$ prey signals but those assumptions remain to be tested (Maler, 2009b). Coding accuracy could also be optimized and a noise-reducing mechanism to do so has been identified. The spiking pattern of electroreceptors at baseline is not random and displays negative serial correlation in interspike intervals (i.e. short interval followed by long and vice-versa) due to an adaptation process (Ratnam \& Nelson, 2000). This pattern reduces the low-frequency content of baseline noise, thus enhancing the ability to detect the low-frequency signals typical of prey stimuli (Chacron, Lindner, Maler, Longtin, \& Bastian, 2005; Chacron, Longtin, \& Maler, 2001). It was further suggested that prey signals would cause a slight disruption in this patterned receptor spike train and that pyramidal cells could extract this change in pattern (Jung et al., 2016; Nesse, Marsat, Longtin, \& Maler, 2012). Although these mechanisms were revealed by focusing on prey capture mechanisms, they are also relevant to the detection of distant conspecific signals and we expect that these concepts will be explored when investigating the mechanisms permitting sensitive conspecific detection and localization.

\section{Network dynamic and spatial processing}

Localization of a passive object like prey differs from localizing the active signal of a conspecific for several reasons. The sensing volume for prey or small passive objects is limited to a few cm around the body and even large objects, such as a tank wall, do not significantly affect the strength of the EOD signal when it is more than $10 \mathrm{~cm}$ away (Chen et al., 2005; Fotowat et al., 2013). Passive objects that are detected cause a disturbance of the EOD over a limited area of the skin (a spot for a prey, one side of the body for a wall, etc.). In contrast, a 
Spatial Processing in the Electrosensory System

conspecific at distances of more than $10 \mathrm{~cm}$ causes a very diffuse image where the signal strength at most points on the receiver's body differs only by small amounts (Pedraja et al., 2016). Furthermore, the shape of the electric image of an object relates to the shape of the object in a straightforward way; for example, a sphere will cause a round "shadow" on the sensory surface. Active conspecific signals will cause a complex activation pattern of the sensory surface because of the relative orientation of the sender fish EO and cutaneous receptor orientation. Consequently, two receptors situated equally far from the sender could perceive signals of very different strengths if they are oriented differently (e.g. along the ventral-dorsal axis for receptors on the back and medial-lateral for receptors on the side). In other words, the activation of the receptor array is not simply related to the xyz position of the conspecific but also to its orientation.

Nevertheless, no matter what the relationship is between pattern of activation of the array of receptors and conspecific location, it carries the spatial information necessary for localization. As described above, the feedforward circuit preserves a spatially accurate representation of the sensory image due to its localized receptive field. The ELL network contains a variety of elements that can influence spatial representation, each driven by more or less localized receptive fields (Fig 5). Most notably, two types of feedback inputs are known to influence pyramidal cell responses. While the feedback pathway through bipolar cells of the nP is poorly understood, the inputs from stellate cells are well characterized. It is driven by a receptive field slightly larger than the pyramidal cell it projects to. This feedback has been proposed to function as a "searchlight" (Berman \& Maler, 1999) and recent papers by (Clarke et al., 2014; Clarke \& Maler, 2017) demonstrated how this feedback enhances the response to moving prey-like stimuli. This mechanism could also play a role in shaping the response to conspecifics in close proximity, but it is unlikely that it will affect responses to more distant individuals since its modus operandi relies on the activation of relatively small receptive fields. The feedback through nP's stellate cells has also been shown to enhance the response to envelope signals elicited by moving conspecifics (Metzen et al., 2018). The authors of this study showed that the sensitivity of a specific electromotor reaction to the envelope signals of medium to low strength (10-15\% contrast) required this input. A 10-15\% contrast corresponds to a fish 20-25 cm away (Fotowat et al., 2013) and it is unclear how this feedback affects the processing of signals from more distant individuals. Nevertheless, it would be interesting to determine whether this feedback pathway 


\section{Spatial Processing in the Electrosensory System}

shapes the spatial representation of conspecific signals, particularly for a conspecific at short to medium distances.

The indirect feedback through the EGp is described in the section above as mediating a cancellation of the response to beats, and thus could also affect the spatial representation of conspecific signals. The precise extent of the receptive field driving this feedback has been shown to be very large and thus is well suited to provide an input that reflects the activation pattern over a large area of the sensory surface. As described in the next section, this type of spatially diffuse input has been shown in other systems to shape spatial processing through background suppression and contrast enhancement, so we suggest it could influence spatial representation in this system too.

\section{Discussion}

We have outlined some of the challenges faced by weakly electric fish when trying to detect and locate a conspecific and presented some of the mechanisms involved in spatial processing in this system. We have argued in the introduction that the electrosensory system can compare in some ways with the visual system but in others with the auditory system. We hope that some of the insight presented along the way has reinforced this statement. For example, we pointed out that topographic mapping from the periphery all the way to the optic tectum that can guide locomotion is a featured shared with the visual system. On the other hand, the auditory system must "compute space" by comparing the signal at the two ears. For conspecific signals that are not in the immediate vicinity, this same process must happen and considering the shared developmental and evolutionary origins we speculate that solutions to this common problem could share some features. To stress further the potential for insight we can obtain from comparing these sensory systems, we point out below a few important mechanisms that the auditory or visual system utilizes to perform challenging tasks and explain how they can relate to the electrosensory system.

Sound localization has been thoroughly studied in a variety of systems but research on the barn owl, with its exquisite accuracy in sound localization, has a particularly rich history of insightful studies (Grothe, 2018). Research by Konishi, Knudsen, Carr and others have unraveled how the interaural time differences (ITD) of sound arrival at each ear, and interaural level 


\section{Spatial Processing in the Electrosensory System}

differences (i.e. amplitude; ILD) enhanced, combined and how they support localization accuracy of just a few degrees (Carr \& Konishi, 1990; Knudsen, 1981; Konishi, 1973). This corresponds to ITDs of a few $\mu$ s and champions the sensitivity of most vertebrates' auditory systems. In this system, localization on the vertical plane (elevation) relies heavily on ILD and sensitivity to these cues first arises in the posterior nucleus of the ventral lateral lemniscus where neurons receive excitation from one ear and inhibition from the other (Takahashi \& Keller, 1992). In mammals, ILD sensitivity contributes to the localization on the horizontal plan (at least for high frequency sounds) and a binaural comparison occurs in the Lateral Superior Olive. There, excitatory inhibitory inputs combine with contralateral inhibitory inputs dirven indirectly by globular bushy cells driven by a large number of auditory receptors (Grothe \& Pecka, 2014) Contralateral inhibition enhancing binaural contrast is common in auditory systems and can interact with the temporal processing of the signals (Koch \& Grothe, 2000) to enhance sound localization specifically for behaviorally relevant signal patterns (G Marsat \& Pollack, 2005). The neural circuitry to perform a similar operation is present in the ELL of knifefish (Fig 6). The indirect feedback is driven by spatially diffuse inputs and can attenuate the response to conspecific signals particularly relevant in some interactions (i.e. low frequency beats). For a pyramidal cell that is only weakly excited by the conspecific signal because it is not ideally located relative to the conspecific location, the feedback might draw its inputs from a region that is maximally stimulated by the conspecific and thus the beat would be effectively cancelled in these pyramidal cells. For cells strongly excited by the feedforward stimulation from the conspecific, the feedback might not completely cancel the beat response. Although this mechanism is simply a hypothesis and remains to be tested, the elements to implement it seem to be present.

Beyond localizing a single signal, the auditory system might be faced with the "cocktail party problem" where it must attend to one signal among many (Cherry, 1953). The mechanisms allowing the resolution of this issue have also been thoroughly investigated (e.g. Middlebrooks et al., 2017) and still lead to new discoveries regularly (e.g. Popham, Boebinger, Ellis, Kawahara, $\&$ McDermott, 2018). Listening to a communication signal with only one ear in a noisy environment makes extracting the message more difficult than if binaural hearing is used. It is suggested that sound location allows to segregate elements from one stream and top-down feedback inputs allow the enhanced coding of this signal stream (for a review on the topics see 


\section{Spatial Processing in the Electrosensory System}

Haykin \& Chen, 2005). Although most of the mechanisms suggested to contribute to solving the cocktail party problem focused on cortical network, mechanisms present as early as the dorsal cochlear nucleus have been suggested (Pressnitzer, Sayles, Micheyl, \& Winter, 2008).

Observation of electric fish among conspecifics clearly begs the question of how this issue is solved in the electrosensory system. Considering the proposed role of the direct feedback input from nP as a "searchlight" mechanism (a sort of low-level spatial attention mechanism) we suggest that it could contribute to segregating competing signals by enhancing the response (as in Metzen et al., 2018) to the most salient one.

Mechanisms of scene analysis, such as the ones involved in solving the cocktail party problem, are also central issues in visual processing. In particular, foreground-background separation is required when trying to attend to an object - when fixating a moving object for example. Background suppression is largely influenced by the activity of wide field, polyaxonal amacrine cells. These polyaxonal amacrine cells mediate retinal ganglion cell (RGC) selectivity of an object over the background (Ölveczky et al., 2003). This background suppression mechanism relies on the amacrine cells receiving input from a wide RF surround and suppressing RGC activity (Baccus, Olveczky, Manu, \& Meister, 2008). As in the auditory mechanism described above, or the electrosensory mechanisms hypothesized, this visual mechanism enhancing spatial processing relies on inhibition with a different receptive field as its target, emphasizing that this contrast enhancement procedure is a common strategy in scene analysis (see Fig 6).

Sensory systems never cease to amaze the experimenters in their extreme sensitivity that has been well documented in auditory systems (Fettiplace \& Hackney, 2006; Hill \& Boyan, 1977; Knudsen \& Konishi, 1979), visual systems (Jacobs et al., 2009), olfactory systems (K C Daly, Carrell, \& Mwilaria, 2007) and others. Mechanisms underlying the ability to detect extremely weak prey stimuli have been identified in weakly electric fish and are likely relevant to the detection of similarly weak conspecific signals. One of the mechanisms identified by Jung et al (2016) relies on a finely balanced inhibition and excitation from feedforward inputs. Balanced inhibition and excitation is a staple feature of many neural networks (e.g. cortex; Haider, 2006) and is involved in shaping sensory tuning in various systems (e.g. Anderson, Carandini, \& Ferster, 2000). We also described how the presence of ISI correlation in receptors 


\section{Spatial Processing in the Electrosensory System}

spike train enhances coding accuracy by decreasing variability, a process observed in a variety of neurons (e.g. Farkhooi, Strube-Bloss, \& Nawrot, 2009). Several other mechanisms enhance the sensitivity of this system but have not been discussed here (e.g. bursting serving the same function in this system as in others; (Krahe \& Gabbiani, 2004) for lack of space or because they are less obviously relevant to processing the spatial aspect of conspecific signals.

Finally, it should be noted that behavioral strategies can contribute to the localization process. A good example of this phenomenon is calling song localization in crickets. Females will approach a song source in zig-zag patterns but the angle of each turn is much greater than the angular resolution of localization in the frontal field (Schöneich \& Hedwig, 2010). This suggest that the cricket lateralizes the sound, turns coarsely in that direction and after a few steps re-evaluates whether the sound is still coming from that side or not. This zig-zag behavioral strategy can thus be explained by the reliance on accurate lateralization rather than all around accurate localization. In elephantnose (mormyrid) electric fish, behavioral strategies might also hint at the sensory mechanism in place. An individual moving towards a conspecific will tend to follow electric field lines rather than moving straight towards it (Schluger \& Hopkins, 1987). This pattern arises presumably from the fish aiming to balance the strength of the electric field on each side of the body. Various active sampling strategies are also used in different organisms to enhance a sensory signal (Schroeder, Wilson, Radman, Scharfman, \& Lakatos, 2010). A well described example is the microsaccades used in the visual system to prevent firing rate adaptation, thereby preventing the fading of visual images representations (Schroeder et al., 2010). Similarly, knifefish use the motions of their body to enhance the localization of nearby objects (Stamper, et al., 2012). Furthermore, Heiligenberg (1975) found that tail bending enhances the electric image/shadow that the object of interest casts on the fish's body (see also Sim \& Kim, 2011). Behavioral tests in knifefish have not yet identified behavioral strategies that are used during conspecific localization specifically (rather than simply object localization) and could be the topic of future experiments. In particular, it would be useful to test explicitly whether the fish can accurately localize other distant individuals at any azimuth or if they simply rely on a lateralization of the signals.

In conclusion, we would like to reiterate that weakly electric fish accomplish difficult tasks when detecting and localizing conspecifics. Many of these challenges resemble those faced 
Spatial Processing in the Electrosensory System

by most modalities but the particularities of the electrosense allows us to probe the generality versus specificity of mechanisms observed across these sensory systems. Researchers studying weakly electric fish are continuing to build on a rich history of contribution to our understanding of behavior and its neural basis. Spatial processing in this system is one of the lines of research that has many unanswered questions and the potential for insightful discoveries. 


\section{Spatial Processing in the Electrosensory System}

\section{References}

Allen, K. M., \& Marsat, G. (2018). Task-specific sensory coding strategies are matched to detection and discrimination performance. The Journal of Experimental Biology, 221(6), jeb170563.

https://doi.org/10.1242/jeb.170563

Anderson, J. S., Carandini, M., \& Ferster, D. (2000). Orientation Tuning of Input Conductance, Excitation, and Inhibition in Cat Primary Visual Cortex. Journal of Neurophysiology, 84(2), 909-926. https://doi.org/10.1152/jn.2000.84.2.909

Aragón, P. (2009). Conspecific male chemical cues influence courtship behaviour in the male newt Lissotriton boscai. Behaviour, 146(8), 1137-1151. https://doi.org/10.1163/156853909X413097

Arikawa, K., Wakakuwa, M., Qiu, X. D., Kurasawa, M., \& Stavenga, D. G. (2005). Sexual dimorphism of shortwavelength photoreceptors in the small white butterfly, Pieris rapae crucivora. Journal of Neuroscience, 25(25), 5935-5942. https://doi.org/Doi 10.1523/Jneurosci.1364-05.2005

Assad, C., \& Bower, J. M. (1997). Electric field maps and boundary element simulations of electrolocation in weakly electric fish. Engineering and Applied Science. https://doi.org/10.1080/01639374.2011.545343

Babineau, D., Lewis, J. E., \& Longtin, A. (2007). Spatial Acuity and Prey Detection in Weakly Electric Fish. PLoS Computational Biology, 3(3), e38. https://doi.org/10.1371/journal.pcbi.0030038

Baccus, S. A., Olveczky, B. P., Manu, M., \& Meister, M. (2008). A retinal circuit that computes object motion. The Journal of Neuroscience : The Official Journal of the Society for Neuroscience, 28(27), 6807-17. https://doi.org/10.1523/JNEUROSCI.4206-07.2008

Baker, C. V. H., Modrell, M. S., \& Gillis, J. A. (2013). The evolution and development of vertebrate lateral line electroreceptors. Journal of Experimental Biology, 216(13), 2515-2522. https://doi.org/10.1242/jeb.082362

Bastian, J. (1986). Gain control in the electrosensory system: a role for the descending projections to the electrosensory lateral line lobe. Journal of Comparative Physiology A, 158(4), 505-515.

https://doi.org/10.1007/BF00603796

Bastian, J. (1986). Gain control in the electrosensory system mediated by descending inputs to the electrosensory lateral line lobe. The Journal of Neuroscience : The Official Journal of the Society for Neuroscience, 6(2), 553-62. Retrieved from http://www.ncbi.nlm.nih.gov/pubmed/3950710

Bastian, J., Chacron, M. J., \& Maler, L. (2002). Receptive field organization determines pyramidal cell stimulusencoding capability and spatial stimulus selectivity. Journal of Neuroscience, 22(11), 4577-4590.

Bee, M. A. (2000). Male green frogs lower the pitch of acoustic signals in defense of territories: a possible dishonest signal of size? Behavioral Ecology, 11(2), 169-177. https://doi.org/10.1093/beheco/11.2.169

Behr, O., Knörnschild, M., \& Von Helversen, O. (2009). Territorial counter-singing in male sac-winged bats saccopteryx bilineata: Low-frequency songs trigger a stronger response. Behavioral Ecology and Sociobiology, 63(3), 433-442. https://doi.org/10.1007/s00265-008-0677-2

Bell, C. C., \& Maler, L. (2005). Central neuroanatomy of electrosensory systems in fish. In T. H. Bullock, C. D. Hopkins, A. N. Popper, \& R. R. Fay (Eds.), Electroreception (Vol. 21, pp. 68-111). New York: Springer. https://doi.org/10.1007/0-387-28275-0

Benda, J., Longtin, A., \& Maler, L. (2006). A synchronization-desynchronization code for natural communication signals. Neuron, 52(2), 347-358. https://doi.org/10.1016/j.neuron.2006.08.008

Bennett, M. V. L. (1971). Electroreception. Fish Physiology, 5, 493-574. https://doi.org/10.1016/S15465098(08)60052-7 
Spatial Processing in the Electrosensory System

Bennett, M. V. L., Sandri, C., \& Akert, K. (1989). Fine structure of the tuberous electroreceptor of the highfrequency electric fish, Sternarchus albifrons (gymnotiformes). Journal of Neurocytology, 18(2), 265-283. https://doi.org/10.1007/BF01206667

Berman, N. J., \& Maler, L. (1999). Neural architecture of the electrosensory lateral line lobe: adaptations for coincidence detection, a sensory searchlight and frequency-dependent adaptive filtering. Journal of Experimental Biology, 202(10), 1243-1253. Retrieved from papers3://publication/uuid/C8815D56-99844BB3-ABB7-30D99117FEEF

Bodznick, D., \& Northcutt, R. G. (1981). Electroreception in lampreys: evidence that the earliest vertebrates were electroreceptive. Science, 212(4493), 465-467. https://doi.org/10.1126/science.7209544

Bol, K., Marsat, G., Harvey-Girard, E., Longtin, A., \& Maler, L. (2011). Frequency-Tuned Cerebellar Channels and Burst-Induced LTD Lead to the Cancellation of Redundant Sensory Inputs. Journal of Neuroscience, 31(30), 11028-11038. https://doi.org/10.1523/Jneurosci.0193-11.2011

Bradbury, J. W., \& Vehrencamp, S. L. (2011). Principles of animal communication (2nd ed.). Sunderland, Mass., Mass.: Sinauer Associates.

Brand, A., Behrend, O., Marquardt, T., McAlpine, D., \& Grothe, B. (2002). Precise inhibition is essential for microsecond interaural time difference coding. Nature, 417(6888), 543-547.

https://doi.org/10.1038/417543a

Bullock, T. H., Hopkins, C. D., Popper, A. N., \& Fay, R. R. (1986). Electroreception. Eletroreception. https://doi.org/10.1007/0-387-28275-0

Byrne, P. G., \& Keogh, J. S. (2007). Terrestrial toadlets use chemosignals to recognize conspecifics, locate mates and strategically adjust calling behaviour. Animal Behaviour, 74(5), 1155-1162.

https://doi.org/https://doi.org/10.1016/j.anbehav.2006.10.033

Caputi, A. A., Aguilera, P. A., Carolina Pereira, A., \& Rodríguez-Cattáneo, A. (2013). On the haptic nature of the active electric sense of fish. Brain Research, 1536, 27-43. https://doi.org/10.1016/J.BRAINRES.2013.05.028

Caputi, A. A., \& Budelli, R. (2006). Peripheral electrosensory imaging by weakly electric fish. Journal of Comparative Physiology A, 192(6), 587-600. https://doi.org/10.1007/s00359-006-0100-2

Carlson, B. A., \& Kawasaki, M. (2007). Behavioral responses to jamming and "phantom" jamming stimuli in the weakly electric fish Eigenmannia. Journal of Comparative Physiology A: Neuroethology, Sensory, Neural, and Behavioral Physiology, 193(9), 927-941. https://doi.org/10.1007/s00359-007-0246-6

Carr, C. E., \& Konishi, M. (1990). A circuit for detection of interaural time differences in the brain stem of the barn owl. The Journal of Neuroscience : The Official Journal of the Society for Neuroscience, 10(10), 3227-46. Retrieved from http://www.ncbi.nlm.nih.gov/pubmed/2213141

Carr, C. E., Maler, L., Heiligenberg, W., \& Sas, E. (1981). Laminar organization of the afferent and efferent systems of the torus semicircularis of Gymnotiform fish: Morphological substrates for parallel processing in the electrosensory system. Journal of Comparative Neurology, 203(4), 649-670.

https://doi.org/10.1002/cne.902030406

Carr, C. E., Maler, L., \& Sas, E. (1982). Peripheral organization and central projections of the electrosensory nerves in gymnotiform fish. Journal of Comparative Neurology, 211(2), 139-153. https://doi.org/10.1002/cne.902110204

Cäsar, C., Zuberbühler, K., Young, R. J., \& Byrne, R. W. (2013). Titi monkey call sequences vary with predator location and type. Biology Letters, 9(5). https://doi.org/10.1098/rsbl.2013.0535 
Spatial Processing in the Electrosensory System

Castelló, M. E., Aguilera, P. A., Trujillo-Cenóz, O., \& Caputi, A. A. (2016). Electroreception in Gymnotus carapo: prereceptor processing and the distribution of electroreceptor types. The Journal of Experimental Biology, 21(Pt 21), 3279-87. https://doi.org/10.3109/14659891.2015.1122101

Chacron, M. J., \& Bastian, J. (2008). Population coding by electrosensory neurons. Journal of Neurophysiology, 99(4), 1825-1835. https://doi.org/DOI 10.1152/jn.01266.2007

Chacron, M. J., Doiron, B., Maler, L., Longtin, A., \& Bastian, J. (2003). Non-classical receptive field mediates switch in a sensory neuron's frequency tuning. Nature, 423(6935), 77-81. https://doi.org/10.1038/Nature01590

Chacron, M. J., Lindner, B., Maler, L., Longtin, A., \& Bastian, J. (2005). Experimental and theoretical demonstration of noise shaping by interspike interval correlations. Fluctuations and Noise in Biological, Biophysical, and Biomedical Systems III, 5841, 150-163. https://doi.org/Doi 10.1117/12.610938

Chacron, M. J., Longtin, A., \& Maler, L. (2001). Negative Interspike Interval Correlations Increase the Neuronal Capacity for Encoding Time-Dependent Stimuli. The Journal of Neuroscience, 21(14), 5328-5343. https://doi.org/10.1523/JNEUROSCI.21-14-05328.2001

Chacron, M. J., Maler, L., \& Bastian, J. (2005). Feedback and feedforward control of frequency tuning to naturalistic stimuli. Journal of Neuroscience, 25(23), 5521-5532. https://doi.org/Doi 10.1523/Jneurosci.0445-05.2005

Chen, L., House, J. L., Krahe, R., \& Nelson, M. E. (2005). Modeling signal and background components of electrosensory scenes. Journal of Comparative Physiology. A, Sensory, Neural, and Behavioral Physiology, 191(4), 331-345. https://doi.org/10.1007/s00359-004-0587-3

Cherry, E. C. (1953). Some Experiments on the Recognition of Speech, with One and with Two Ears. The Journal of the Acoustical Society of America, 25(5), 975-979. https://doi.org/10.1121/1.1907229

Cichy, R. M., \& Teng, S. (2017). Resolving the neural dynamics of visual and auditory scene processing in the human brain: A methodological approach. Philosophical Transactions of the Royal Society B: Biological Sciences, 372(1714). https://doi.org/10.1098/rstb.2016.0108

Clarke, S. E., Longtin, A., \& Maler, L. (2014). A Neural Code for Looming and Receding Motion Is Distributed over a Population of Electrosensory ON and OFF Contrast Cells. Journal of Neuroscience, 34(16), 5583-5594. https://doi.org/10.1523/JNEUROSCI.4988-13.2014

Clarke, S. E., \& Maler, L. (2017). Feedback Synthesizes Neural Codes for Motion. Current Biology, 27(9), 1356-1361. https://doi.org/10.1016/j.cub.2017.03.068

Daly, K. C., Bradley, S., Chapman, P. D., Staudacher, E. M., Tiede, R., \& Schachtner, J. (2016). Space Takes Time: Concentration Dependent Output Codes from Primary Olfactory Networks Rapidly Provide Additional Information at Defined Discrimination Thresholds. Frontiers in Cellular Neuroscience, 9, 515. https://doi.org/10.3389/fncel.2015.00515

Daly, K. C., Carrell, L. A., \& Mwilaria, E. (2007). Detection versus perception: physiological and behavioral analysis of olfactory sensitivity in the moth (Manduca sexta). Behavioral Neuroscience, 121(4), 794-807. https://doi.org/2007-11112-016 [pii]10.1037/0735-7044.121.4.794

de Bruyne, M., \& Baker, T. C. (2008). Odor detection in insects: Volatile codes. Journal of Chemical Ecology, 34(7), 882-897. https://doi.org/DOI 10.1007/s10886-008-9485-4

Doucet, S. M., Mennill, D. J., \& Hill, G. E. (2007). The Evolution of Signal Design in Manakin Plumage Ornaments. The American Naturalist, 169(S1), S62-S80. https://doi.org/10.1086/510162

Duncan, J. S., \& Fritzsch, B. (2012). Evolution of sound and balance perception: Innovations that aggregate single hair cells into the ear and transform a gravistatic sensor into the organ of corti. Anatomical Record, 295(11), 1760-1774. https://doi.org/10.1002/ar.22573 


\section{Spatial Processing in the Electrosensory System}

Dunlap, K. D., DiBenedictis, B. T., \& Banever, S. R. (2010). Chirping response of weakly electric knife fish (Apteronotus leptorhynchus) to low-frequency electric signals and to heterospecific electric fish. The Journal of Experimental Biology, 213(Pt 13), 2234-42. https://doi.org/10.1242/jeb.038653

Engler, G., Fogarty, C. M., Banks, J. R., \& Zupanc, G. K. (2000). Spontaneous modulations of the electric organ discharge in the weakly electric fish, Apteronotus leptorhynchus: a biophysical and behavioral analysis. Journal of Comparative Physiology. A, Sensory, Neural, and Behavioral Physiology, 186(7-8), 645-660. Retrieved from http://www.ncbi.nlm.nih.gov/pubmed/11016781

Engler, G., \& Zupanc, G. (2001). Differential production of chirping behavior evoked by electrical stimulation of the weakly electric fish, Apteronotus leptorhynchus. Journal of Comparative Physiology - A Sensory, Neural, and Behavioral Physiology, 187(9), 747-756. https://doi.org/10.1007/s00359-001-0248-8

Farkhooi, F., Strube-Bloss, M. F., \& Nawrot, M. P. (2009). Serial correlation in neural spike trains: Experimental evidence, stochastic modeling, and single neuron variability. Physical Review E - Statistical, Nonlinear, and Soft Matter Physics, 79(2), 1-10. https://doi.org/10.1103/PhysRevE.79.021905

Fettiplace, R., \& Hackney, C. M. (2006). The sensory and motor roles of auditory hair cells. Nature Reviews Neuroscience, 7(1), 19-29. https://doi.org/10.1038/nrn1828

Fotowat, H., Harrison, R. R., \& Krahe, R. (2013). Statistics of the Electrosensory Input in the Freely Swimming Weakly Electric Fish Apteronotus leptorhynchus. Journal of Neuroscience, 33(34), 13758-13772. https://doi.org/10.1523/JNEUROSCI.0998-13.2013

Gabbiani, F., Metzner, W., Wessel, R., \& Koch, C. (1996). From stimulus encoding to feature extraction in weakly electric fish. Nature, 384(6609), 564-567. https://doi.org/Doi 10.1038/384564a0

Giassi, A. C. C., Ellis, W., \& Maler, L. (2012). Organization of the gymnotiform fish pallium in relation to learning and memory: III. Intrinsic connections. Journal of Comparative Neurology, 520(15), 3369-3394. https://doi.org/10.1002/cne.23108

Gómez-Sena, L., Pedraja, F., Sanguinetti-Scheck, J. I., \& Budelli, R. (2014, April 1). Computational modeling of electric imaging in weakly electric fish: Insights for physiology, behavior and evolution. Journal of Physiology Paris. Elsevier. https://doi.org/10.1016/j.jphysparis.2014.08.009

Grosof, D. H., Shapley, R. M., \& Hawken, M. J. (1993). Macaque V1 neurons can signal “illusory” contours. Nature, 365(6446), 550-552. https://doi.org/10.1038/365550a0

Grothe, B. (2018). How the Barn Owl Computes Auditory Space. Trends in Neurosciences, 41(3), $115-117$. https://doi.org/10.1016/j.tins.2018.01.004

Grothe, B., \& Pecka, M. (2014). The natural history of sound localization in mammals--a story of neuronal inhibition. Frontiers in Neural Circuits, 8, 116. https://doi.org/10.3389/fncir.2014.00116

Guilford, T., \& Dawkins, M. S. (1993). Receiver Psychology and the Design of Animal Signals. Trends in Neurosciences, 16(11), 430-436. https://doi.org/Doi 10.1016/0166-2236(93)90068-W

Haider, B. (2006). Neocortical Network Activity In Vivo Is Generated through a Dynamic Balance of Excitation and Inhibition. Journal of Neuroscience, 26(17), 4535-4545. https://doi.org/10.1523/JNEUROSCI.5297-05.2006

Hartmann, M. J., \& Bower, J. M. (2001). Tactile responses in the granule cell layer of cerebellar folium crus Ila of freely behaving rats. The Journal of Neuroscience, 21(10), 3549-3563. https://doi.org/21/10/3549 [pii]

Harvey-Girard, E., Lewis, J., \& Maler, L. (2010). Burst-induced anti-hebbian depression acts through short-term synaptic dynamics to cancel redundant sensory signals. Journal of Neuroscience, 30(17), 6152-6169. https://doi.org/Doi 10.1523/Jneurosci.0303-10.2010 


\section{Spatial Processing in the Electrosensory System}

Haykin, S., \& Chen, Z. (2005). The Cocktail Party Problem. Neural computation (Vol. 17). https://doi.org/10.1162/0899766054322964

Heiligenberg, W. (1975). Theoretical and experimental approaches to spatial aspects of electrolocation. Journal of Comparative Physiology ? A, 103(3), 247-272. https://doi.org/10.1007/BF00612021

Heiligenberg, W. (1991). Sensory control of behavior in electric fish. Current Opinion in Neurobiology, 1(4), 633637. https://doi.org/10.1016/S0959-4388(05)80041-8

Heiligenberg, W., \& Dye, J. (1982). Labelling of Eleetroreeeptive Afferents in a Gymnotoid Fish by Intraeellular Injection of HRP: The Mystery of Multiple Maps. J Comp Physiol, 148, 287-296. Retrieved from https://link.springer.com/content/pdf/10.1007\%2FBF00679013.pdf

Henninger, J., Krahe, R., Kirschbaum, F., Grewe, J., \& Benda, J. (2018). Statistics of natural communication signals observed in the wild identify important yet neglected stimulus regimes in weakly electric fish. The Journal of Neuroscience. https://doi.org/10.1523/JNEUROSCI.0350-18.2018

Hill, K. G., \& Boyan, G. S. (1977). Sensitivity to frequency and direction of sound in the auditory system of crickets (Gryllidae). Journal of Comparative Physiology, 121(1), 79-97. https://doi.org/10.1007/BF00614182

Hopkins, C. D. (1976). Stimulus filtering and electroreception: Tuberous electroreceptors in three species of Gymnotoid fish. Journal of Comparative Physiology a A, 111(2), 171-207. https://doi.org/10.1007/BF00605531

Huang, C. G., Metzen, M. G., \& Chacron, M. J. (2018). Feedback optimizes neural coding and perception of natural stimuli. ELife, 7(514), 398-7493. https://doi.org/10.7554/eLife.38935

Hupé, G. J., Lewis, J. E., \& Benda, J. (2008). The effect of difference frequency on electrocommunication: Chirp production and encoding in a species of weakly electric fish, Apteronotus leptorhynchus. Journal of Physiology Paris, 102(4-6), 164-172. https://doi.org/DOI 10.1016/j.jphysparis.2008.10.013

Jacobs, A. L., Fridman, G., Douglas, R. M., Alam, N. M., Latham, P. E., Prusky, G. T., \& Nirenberg, S. (2009). Ruling out and ruling in neural codes. Proceedings of the National Academy of Sciences of the United States of America, 106(14), 5936-5941. https://doi.org/0900573106 [pii]10.1073/pnas.0900573106

Jeffress, L. A. (1948). A place theory of sound localization. Journal of Comparative and Physiological Psychology. US: American Psychological Association. https://doi.org/10.1037/h0061495

Jung, S. N., Longtin, A., \& Maler, L. (2016). Weak signal amplification and detection by higher-order sensory neurons. Journal of Neurophysiology, 115(4), 2158-2175. https://doi.org/10.1152/jn.00811.2015

Kelly, M., Babineau, D., Longtin, A., \& Lewis, J. E. (2008). Electric field interactions in pair of electric fish: modeling and mimicking naturalistic inputs. Biological Cybernetics, 98(6), 479-490. https://doi.org/10.1007/s00422008-0218-0

Keyser, A. J., \& Hill, G. E. (2000). Structurally based plumage coloration is an honest signal of quality in male blue grosbeaks. Behavioral Ecology, 11(2), 202-209. https://doi.org/DOI 10.1093/beheco/11.2.202

Knudsen, E. (1974). Behavioral thresholds to electric signals in high frequency electric fish. Journal of Comparative Physiology, 91(4), 333-353. https://doi.org/10.1007/bf00694465

Knudsen, E. I. (1975). Spatial aspects of the electric fields generated by weakly electric fish. Journal of Comparative Physiology ? A, 99(2), 103-118. https://doi.org/10.1007/BF00618178

Knudsen, E. I. (1981). The Hearing of the Barn Owl. Scientific American, 245(6), 112-125. https://doi.org/10.1038/scientificamerican1281-112 


\section{Spatial Processing in the Electrosensory System}

Knudsen, E. I., \& Konishi, M. (1979). Mechanisms of sound localization in the barn owl (Tyto alba). Journal of Comparative Physiology $\square$ A, 133(1), 13-21. https://doi.org/10.1007/BF00663106

Koch, U., \& Grothe, B. (2000). Interdependence of spatial and temporal coding in the auditory midbrain. Journal of Neurophysiology, 83(4), 2300-14. Retrieved from http://www.ncbi.nlm.nih.gov/pubmed/10758135

Kolodziejski, J. a, Sanford, S. E., \& Smith, G. T. (2007). Stimulus frequency differentially affects chirping in two species of weakly electric fish: implications for the evolution of signal structure and function. The Journal of Experimental Biology, 210(Pt 14), 2501-2509. https://doi.org/10.1242/jeb.005272

Konishi, M. (1973). How the Owl Tracks Its Prey: Experiments with trained barn owls reveal how their acute sense of hearing enables them to catch prey in the dark. American Scientist, 61(4), 414-424. Retrieved from http://www.jstor.org/stable/27843880

Konishi, M. (1985). Birdsong: From Behavior to Neuron. Annual Review of Neuroscience, 8(1), 125-170. https://doi.org/10.1146/annurev.ne.08.030185.001013

Krahe, R., Bastian, J., \& Chacron, M. J. (2008). Temporal processing across multiple topographic maps in the electrosensory system. Journal of Neurophysiology, 100(2), 852-867. https://doi.org/10.1152/jn.90300.2008

Krahe, R., \& Gabbiani, F. (2004). Burst firing in sensory systems. Nature Reviews Neuroscience, 5(1), 13-23. https://doi.org/10.1038/nrn1296

Krahe, R., \& Maler, L. (2014). Neural maps in the electrosensory system of weakly electric fish. Current Opinion in Neurobiology, 24, 13-21. https://doi.org/10.1016/j.conb.2013.08.013

Kramer, B. (1996). Electroreception and communication in fishes. Progress in Zoology (Vol. 42). Gustav Fischer. Retrieved from https://epub.uni-regensburg.de/2108/

Krekelberg, B., Kubischik, M., Hoffmann, K., \& Bremmer, F. (2003). Neural correlates of visual localization and perisaccadic mislocalization, 37, 537-545.

Lannoo, M. J., Maler, L., \& Tinner, B. (1989). Ganglion cell arrangement and axonal trajectories in the anterior lateral line nerve of the weakly electric fish Apteronotus leptorhynchus (Gymnotiformes). Journal of Comparative Neurology, 280(3), 331-342. https://doi.org/10.1002/cne.902800302

Liberman, A. M., Harris, K. S., Hoffman, H. S., \& Griffith, B. C. (1957). The Discrimination of Speech Sounds within and across Phoneme Boundaries. Journal of Experimental Psychology, 54(5), 358-368. https://doi.org/Doi 10.1037/H0044417

Lissmann, H. W. (1958). On the Function and Evolution of Electric Organs in Fish. Journal of Experimental Biology, 35(1), 156-.

Lissmann, H. W. (1963). Electric Location by Fishes. Scientific American, 208(3), 50-59. https://doi.org/10.1038/scientificamerican0363-50

Lohr, B., Wright, T. F., \& Dooling, R. J. (2003). Detection and discrimination of natural calls in masking noise by birds: Estimating the active space of a signal. Animal Behaviour, 65(4), 763-777.

https://doi.org/10.1006/anbe.2003.2093

Lohuis, T. D., \& Fuzessery, Z. M. (2000). Neuronal sensitivity to interaural time differences in the sound envelope in the auditory cortex of the pallid bat. Hearing Research, 143(1-2), 43-57. https://doi.org/10.1016/S03785955(00)00021-6

Maler, L. (2009). Receptive field organization across multiple electrosensory maps. I. Columnar organization and estimation of receptive field size. Journal of Comparative Neurology, 516(5), 376-393.

https://doi.org/10.1002/cne.22124 


\section{Spatial Processing in the Electrosensory System}

Maler, L. (2009). Receptive field organization across multiple electrosensory maps. II. Computational analysis of the effects of receptive field size on prey localization. Journal of Comparative Neurology, 516(5), 394-422. https://doi.org/10.1002/cne.22120

Maler, L., Sas, E. K. B., \& Rogers, J. (1981). The cytology of the posterior lateral line lobe of high-frequency weakly electric fish (gymnotidae): Dendritic differentiation and synaptic specificity in a simple cortex. The Journal of Comparative Neurology, 195(1), 87-139. https://doi.org/10.1002/cne.901950107

Marsat, G., Longtin, A., \& Maler, L. (2012). Cellular and circuit properties supporting different sensory coding strategies in electric fish and other systems. Current Opinion in Neurobiology, 22(4), 686-692. https://doi.org/10.1016/j.conb.2012.01.009

Marsat, G., \& Maler, L. (2010). Neural heterogeneity and efficient population codes for communication signals. Journal of Neurophysiology, 104(5), 2543-2555. https://doi.org/jn.00256.2010 [pii]10.1152/jn.00256.2010

Marsat, G., \& Pollack, G. S. (2005). Effect of the temporal pattern of contralateral inhibition on sound localization cues. Journal of Neuroscience, 25(26), 6137-6144. https://doi.org/10.1523/Jneurosci.0646-05.2005

Marsat, G., Proville, R. D., \& Maler, L. (2009). Transient signals trigger synchronous bursts in an identified population of neurons. Journal of Neurophysiology, 102(2), 714-723. https://doi.org/10.1152/jn.91366.2008

Mathis, A. (1990). Territorial salamanders assess sexual and competitive information using chemical signals. Animal Behaviour, 40(5), 953-962. https://doi.org/https://doi.org/10.1016/S0003-3472(05)80997-2

McGregor, P. K. (1993). Signalling in territorial systems: a context for individual identification, ranging and eavesdropping. Philosophical Transactions - Royal Society of London, B, 340(1292), 237-244. https://doi.org/10.1098/rstb.1993.0063

Metzen, M. G., \& Chacron, M. J. (2014). Weakly electric fish display behavioral responses to envelopes naturally occurring during movement: implications for neural processing. J. Exp. Biol., 217(Pt 8), 1381-1391. https://doi.org/10.1242/jeb.098574

Metzen, M. G., Huang, C. G., \& Chacron, M. J. (2018). Descending pathways generate perception of and neural responses to weak sensory input. PLOS Biology, 16(6), e2005239.

Metzner, W. (1999). Neural circuitry for communication and jamming avoidance in gymnotiform electric fish. The Journal of Experimental Biology, 202(Pt 10), 1365-1375.

Metzner, W., \& Juranek, J. (1997). A sensory brain map for each behavior? Proceedings of the National Academy of Sciences, 94(26).

Middleton, J. W., Longtin, A., Benda, J., \& Maler, L. (2006). The cellular basis for parallel neural transmission of a high-frequency stimulus and its low-frequency envelope. Proceedings of the National Academy of Sciences of the United States of America, 103(39), 14596-14601. https://doi.org/DOI 10.1073/pnas.0604103103

Modrell, M. S., Bemis, W. E., Northcutt, R. G., Davis, M. C., \& Baker, C. V. H. (2011). Electrosensory ampullary organs are derived from lateral line placodes in bony fishes. Nature Communications, 2(1), 3142-3146. https://doi.org/10.1038/ncomms1502

Nelson, M. E., \& Maclver, M. A. (1999). Prey capture in the weakly electric fish Apteronotus albifrons: Sensory acquisition strategies and electrosensory consequences. The Journal of Experimental Biology, 202(10), 1195-203. https://doi.org/PMID: 10210661

Nelson, M. E., Maclver, M. A., \& Coombs, S. (2002). Modeling Electrosensory and Mechanosensory Images during the Predatory Behavior of Weakly Electric Fish. Brain, Behavior and Evolution, 59(4), 199-210. https://doi.org/10.1159/000064907 
Spatial Processing in the Electrosensory System

Nelson, M. E., Xu, Z., \& Payne, J. R. (1997). Characterization and modeling of P-type electrosensory afferent responses to amplitude modulations in a wave-type electric fish. Journal of Comparative Physiology ANeuroethology Sensory Neural and Behavioral Physiology, 181(5), 532-544. Retrieved from http://www.ncbi.nlm.nih.gov/entrez/query.fcgi?cmd=Retrieve\&db=PubMed\&dopt=Citation\&list_uids=9373 958

Nesse, W. H., Marsat, G., Longtin, A., \& Maler, L. (2012). Detection of weak sensory signals by molecular dynamic transformations of interspike interval sequence. In Cosyne (p. III-73). Salt Lake City.

Okada, J., \& Toh, Y. (2006). Active tactile sensing for localization of objects by the cockroach antenna. Journal of Comparative Physiology A: Neuroethology, Sensory, Neural, and Behavioral Physiology, 192(7), 715-726. https://doi.org/10.1007/s00359-006-0106-9

Ölveczky, B. P., Baccus, S. A., \& Meister, M. (2003). Segregation of object and background motion in the retina. Nature, 423(6938), 401-408. https://doi.org/10.1038/nature01652

Pedraja, F., Perrone, R., Silva, A., \& Budelli, R. (2016). Passive and active electroreception during agonistic encounters in the weakly electric fish Gymnotus omarorum. Bioinspiration and Biomimetics, 11(6), 065002. https://doi.org/10.1088/1748-3190/11/6/065002

Petzold, J. M. J. M., Marsat, G., \& Smith, G. T. T. (2016). Co-adaptation of electric organ discharges and chirps in South American ghost knifefishes (Apteronotidae), 110(3). https://doi.org/10.1016/j.jphysparis.2016.10.005

Popham, S., Boebinger, D., Ellis, D. P. W., Kawahara, H., \& McDermott, J. H. (2018). Inharmonic speech reveals the role of harmonicity in the cocktail party problem. Nature Communications, 9(1). https://doi.org/10.1038/s41467-018-04551-8

Postlethwaite, C. M., Psemeneki, T. M., Selimkhanov, J., Silber, M., \& Maclver, M. A. (2009). Optimal movement in the prey strikes of weakly electric fish: A case study of the interplay of body plan and movement capability. Journal of the Royal Society Interface, 6(34), 417-433. https://doi.org/10.1098/rsif.2008.0286

Pressnitzer, D., Sayles, M., Micheyl, C., \& Winter, I. M. (2008). Perceptual Organization of Sound Begins in the Auditory Periphery. Current Biology, 18(15), 1124-1128. https://doi.org/10.1016/j.cub.2008.06.053

Rasnow, B. (1996). The effects of simple objects on the electric field of Apteronotus. Journal of Comparative Physiology A, 178(3), 397-411. https://doi.org/10.1007/BF00193977

Rasnow, B., Assad, C., \& Bower, J. M. (1993). Phase and amplitude maps of the electric organ discharge of the weakly electric fish, Apteronotus leptorhynchus. Journal of Comparative Physiology A, 172(4), 481-491. https://doi.org/10.1007/BF00213530

Ratnam, R., \& Nelson, M. E. (2000). Nonrenewal statistics of electrosensory afferent spike trains: implications for the detection of weak sensory signals. The Journal of Neuroscience : The Official Journal of the Society for Neuroscience, 20(17), 6672-83. https://doi.org/10.1523/JNEUROSCI.20-17-06672.2000

Reid, J. M., Arcese, P., Cassidy, A. L. E. V., Hiebert, S. M., Smith, J. N. M., Stoddard, P. K., ... Keller, L. F. (2005). Fitness Correlates of Song Repertoire Size in Free-Living Song Sparrows (Melospiza melodia). The American Naturalist, 165(3), 299-310. https://doi.org/10.1086/428299

Saunders, J., \& Bastian, J. (1984). The physiology and morphology of 2 types of electrosensory neurons in the weakly electric fish Apteronotus leptorhynchus. Journal of Comparative Physiology, 154(2), 199-209. https://doi.org/10.1007/BF00604985

Savard, M., Krahe, R., \& Chacron, M. J. (2011). Neural heterogeneities influence envelope and temporal coding at the sensory periphery. Neuroscience, 172, 270-284. https://doi.org/S0306-4522(10)01416-8 [pii]10.1016/j.neuroscience.2010.10.061 
Spatial Processing in the Electrosensory System

Schluger, J. H., \& Hopkins, C. D. (1987). Electric fish approach stationary signal sources by following electric current lines. The Journal of Experimental Biology, 130(December), 359-67. Retrieved from http://www.ncbi.nlm.nih.gov/pubmed/3625122

Schöneich, S., \& Hedwig, B. (2010). Hyperacute directional hearing and phonotactic steering in the cricket (Gryllus bimaculatus deGeer). PLoS ONE, 5(12). https://doi.org/10.1371/journal.pone.0015141

Schroeder, C. E., Wilson, D. A., Radman, T., Scharfman, H., \& Lakatos, P. (2010). Dynamics of Active Sensing and perceptual selection. Current Opinion in Neurobiology, 20(2), 172-176.

https://doi.org/10.1016/J.CONB.2010.02.010

Shumway, C. a. (1989). Multiple electrosensory maps in the medulla of weakly electric gymnotiform fish. I. Physiological differences. J Neurosci, 9(12), 4388-4399. Retrieved from http://www.ncbi.nlm.nih.gov/pubmed/2593005

Sicardi, E. A., Caputi, A. A., \& Budelli, R. (2000). Physical basis of distance discrimination in weakly electric fish. Physica A: Statistical Mechanics and Its Applications, 283(1), 86-93. https://doi.org/10.1016/S03784371(00)00132-1

Sim, M., \& Kim, D. (2011). Electrolocation based on tail-bending movements in weakly electric fish. Journal of Experimental Biology, 214(14), 2443-2450. https://doi.org/10.1242/jeb.052308

Smith, Z. M., Delgutte, B., \& Oxenham, A. J. (2002). Chimaeric sounds reveal dichotomies in auditory perception. Nature, 416(6876), 87-90. https://doi.org/10.1038/416087a

Stamper, S. A., Fortune, E. S., \& Chacron, M. J. (2013). Perception and coding of envelopes in weakly electric fishes. Journal of Experimental Biology, 216(13), 2393-2402. https://doi.org/Doi 10.1242/Jeb.082321

Stamper, S. A., Roth, E., Cowan, N. J., \& Fortune, E. S. (2012). Active sensing via movement shapes spatiotemporal patterns of sensory feedback. Journal of Experimental Biology, 215(9), 1567-1574.

https://doi.org/10.1242/jeb.068007

Stamper, S. a, Madhav, M. S., Cowan, N. J., \& Fortune, E. S. (2012). Beyond the Jamming Avoidance Response: weakly electric fish respond to the envelope of social electrosensory signals. The Journal of Experimental Biology, 215(Pt 23), 4196-207. https://doi.org/10.1242/jeb.076513

Szabo, T. (1974). Anatomy of the Specialized Lateral Line Organs of Electroreception BT - Electroreceptors and Other Specialized Receptors in Lower Vertrebrates. In T. H. Bullock, A. Fessard, P. H. Hartline, A. J. Kalmijn, P. Laurent, R. W. Murray, ... A. Fessard (Eds.) (pp. 13-58). Berlin, Heidelberg: Springer Berlin Heidelberg. https://doi.org/10.1007/978-3-642-65926-3_2

Takahashi, T., \& Keller, C. (1992). Commissural connections mediate inhibition for the computation of interaural level difference in the barn owl. Journal of Comparative Physiology A, 170(2), 161-169. https://doi.org/10.1007/BF00196898

Thomas, R. A., Metzen, M. G., \& Chacron, M. J. (2018). Weakly electric fish distinguish between envelope stimuli arising from different behavioral contexts. The Journal of Experimental Biology, 221(15), jeb178244. https://doi.org/10.1242/jeb.178244

Von Der Emde, G., Schwarz, S., Gomez, L., Budelli, R., \& Grant, K. (1998). Electric fish measure distance in the dark. Nature, 395(6705), 890-894. https://doi.org/10.1038/27655

Vonderschen, K., \& Chacron, M. J. (2011). Sparse and dense coding of natural stimuli by distinct midbrain neuron subpopulations in weakly electric fish. Journal of Neurophysiology, 106(6), 3102-3118. https://doi.org/10.1152/jn.00588.2011 


\section{Spatial Processing in the Electrosensory System}

Walz, H., Grewe, J., \& Benda, J. (2014). Static frequency tuning properties account for changes in neural synchrony evoked by transient communication signals. Journal of Neurophysiology, 112(May), 752-765.

https://doi.org/10.1152/jn.00576.2013

Yu, N., Hupé, G., Garfinkle, C., Lewis, J. E., \& Longtin, A. (2012). Coding Conspecific Identity and Motion in the Electric Sense. PLoS Computational Biology, 8(7), e1002564. Retrieved from http://dx.doi.org/10.1371\%2Fjournal.pcbi.1002564

Zakon, H., Oestreich, J., Tallarovic, S., \& Triefenbach, F. (2002). EOD modulations of brown ghost electric fish: JARs, chirps, rises, and dips. Journal of Physiology, Paris, 96(5-6), 451-8. https://doi.org/10.1016/S09284257(03)00012-3

Zupanc, G. K. H., \& Horschke, I. (1997). Neurons of the posterior subdivision of the nucleus preopticus periventricularis project to the preglomemlar nucleus in the weakly electric fish, Apteronotus leptorhynchus. Brain Research, 774(1-2), 106-115. https://doi.org/10.1016/\$0006-8993(97)81693-9

Zupanc, G. K. H., Sîrbulescu, R. F., Nichols, A., Ilies, I., Sirbulescu, R. F., Nichols, A., \& Ilies, I. (2006). Electric interactions through chirping behavior in the weakly electric fish, Apteronotus leptorhynchus. Journal of Comparative Physiology A: Neuroethology, Sensory, Neural, and Behavioral Physiology, 192(2), 159-173. https://doi.org/10.1007/s00359-005-0058-5 
Spatial Processing in the Electrosensory System

\section{Figures and Legends}

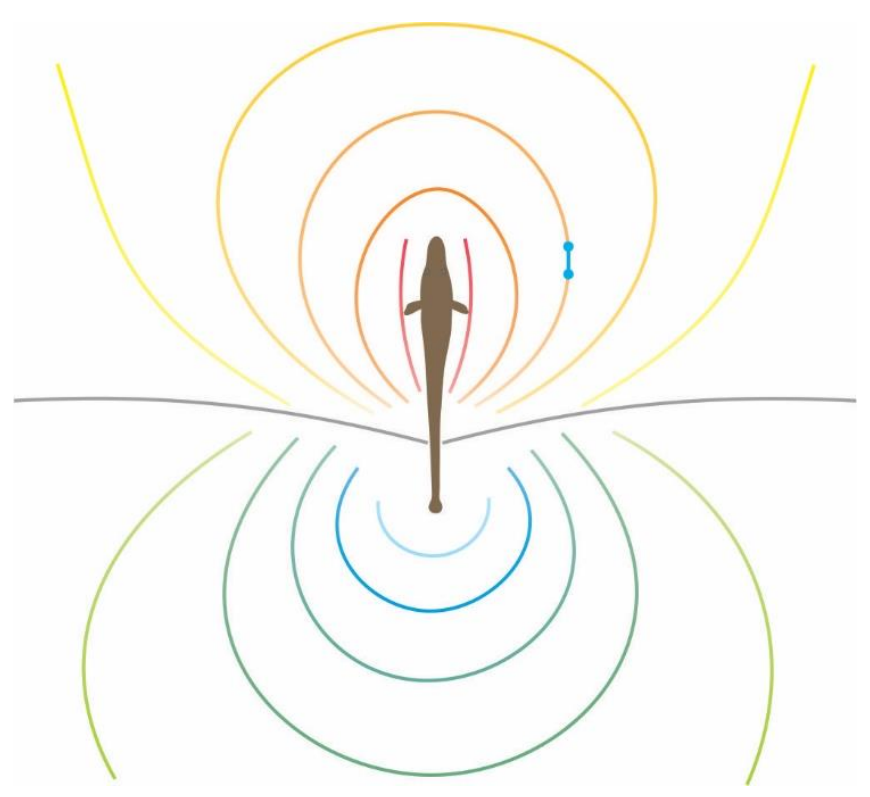

Figure 1. Spatial structure of an Apteronotus leptorhynchus’ weakly electric field.

Illustration of an Apteronotus leptorhynchus, brown ghost knifefish, (center) surrounded by its electric field. Multicolored isopotential lines project outward from the fish. A small receiving dipole (blue) is shown measuring along an isopotential line (orange). The electric field potential is highest close to the fish and decreases as a function of distance. The grey line depicts the zeropotential plane of the fish's electric field. 
Spatial Processing in the Electrosensory System

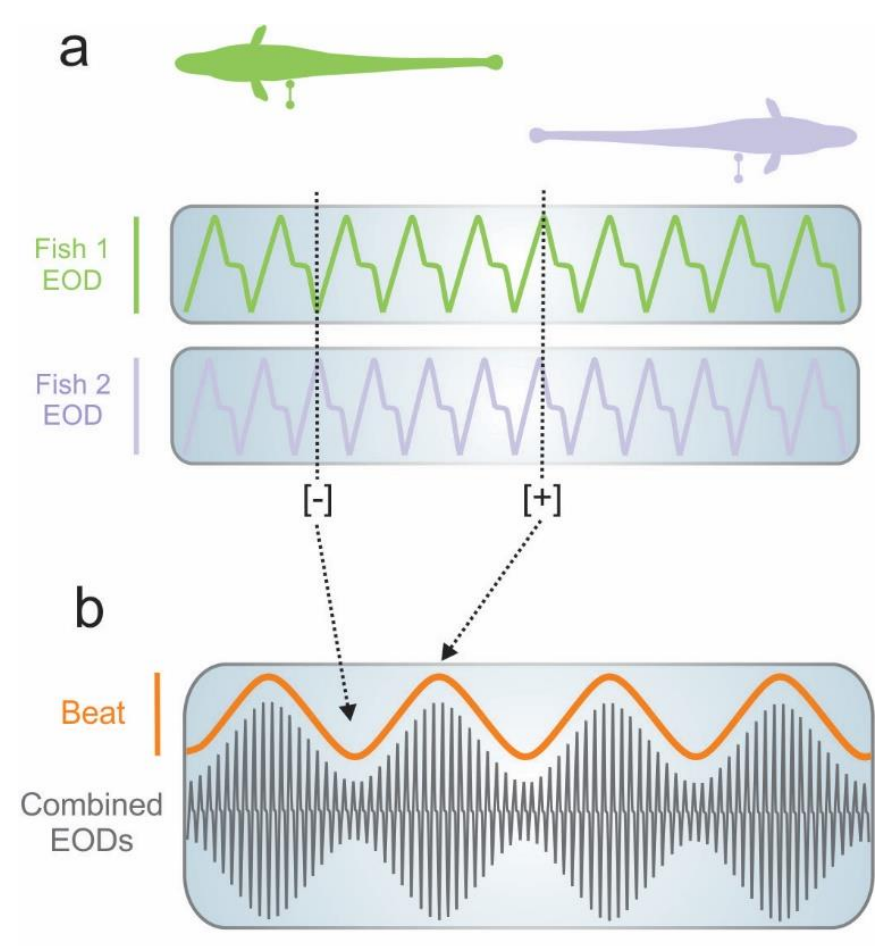

C

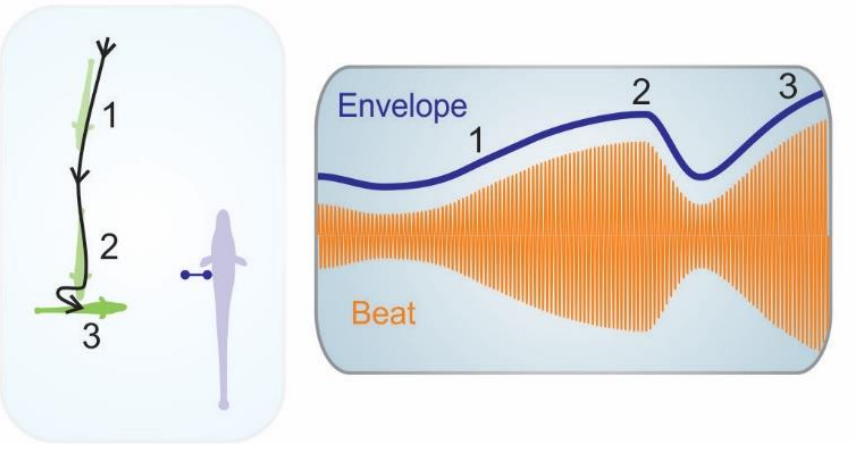

Figure 2. Conspecific signals and the influence of spatial interaction.

(a). Two separate, individual fish are depicted with receiving dipoles (green and purple) measuring their respective EODs. EODs are shown as continuous quasi-sinusoidal waveforms that differ slightly in frequency. Differences in frequency cause changes in phase, as depicted by the dotted black lines. Interactions of EOD waveform peaks and troughs create suppressions and additions in amplitude and are represented by [-] and [+], respectively.

(b). A depiction of the combined EODs of two static fish. Constructive and destructive interferences created by EOD phase differences result in the formation of a "beat" (orange). 
Spatial Processing in the Electrosensory System

Arrows point to examples of decreases and increases of beat strength caused by EOD interactions.

(c). Amplitude modulations of the beat (beat of the beat) result in the formation of an “envelope". Receiving dipole recordings (blue) from a stationary, receiver fish (purple) shows how the envelope strength changes as a function of distance as well as orientation. (1) A distant, sender fish will produce a weaker envelope that increases in strength as the sender fish approaches. (2) Envelope strength greatly increases when the two fish are in close proximity but quickly decreases as the zero potential plane of the sender fish crosses over the receiving dipole. (3) The strength of the envelope is affected not only by distance but also by orientation, with an optimal orientation resulting in greater envelope strength.

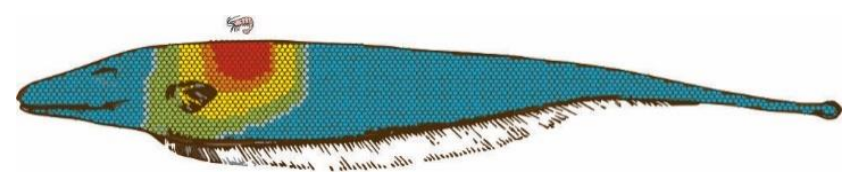

Figure 3. Local activation of the receptor array enables spatial localization of prey. A representation of the tuberous electroreceptor array on an Apteronotus leptorhynchus. Local electrokinetic signals from a small, crustacean-like prey create a gradient of activation along the sensory surface of the body. Warmer and cooler colors depict a higher and lower amount of receptor activation, respectively. This pattern of receptor activity provides sensory information for spatially localizing prey. 
Spatial Processing in the Electrosensory System

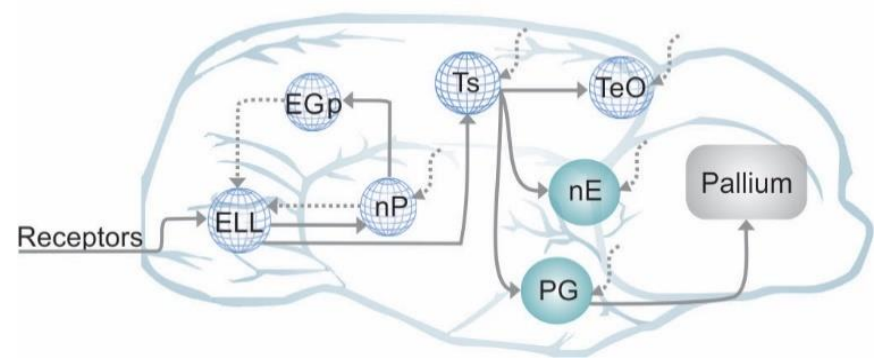

Figure 4. Electrosensory pathway and topographically mapped brain regions.

A depiction of an Apteronotus leptorhynchus brain with labeled brain regions and their respective connections. Electroreceptor afferents provide sensory input to the electrosensory lateral line lobe (ELL). The ELL is topographically mapped (globe symbol) and influenced by indirect feedback from the caudal lobe of the cerebellum (EGp) and by direct feedback from the nucleus praeminentialis (nP). Sensory information from the hindbrain ELL projects to the midbrain torus (Ts). Connections from the Ts project further to the optic tectum (TeO), the nucleus electrosensorius (nE), and the preglomerular nucleus (PG). A topographic organization is conserved to brain regions as far as $\mathrm{TeO}$ but is lost in the forebrain dorsal telencephalon (pallium). Dashed arrows represent brain areas additionally influenced by the pallium, though connections and interactions with the pallium have been less studied. 
Spatial Processing in the Electrosensory System

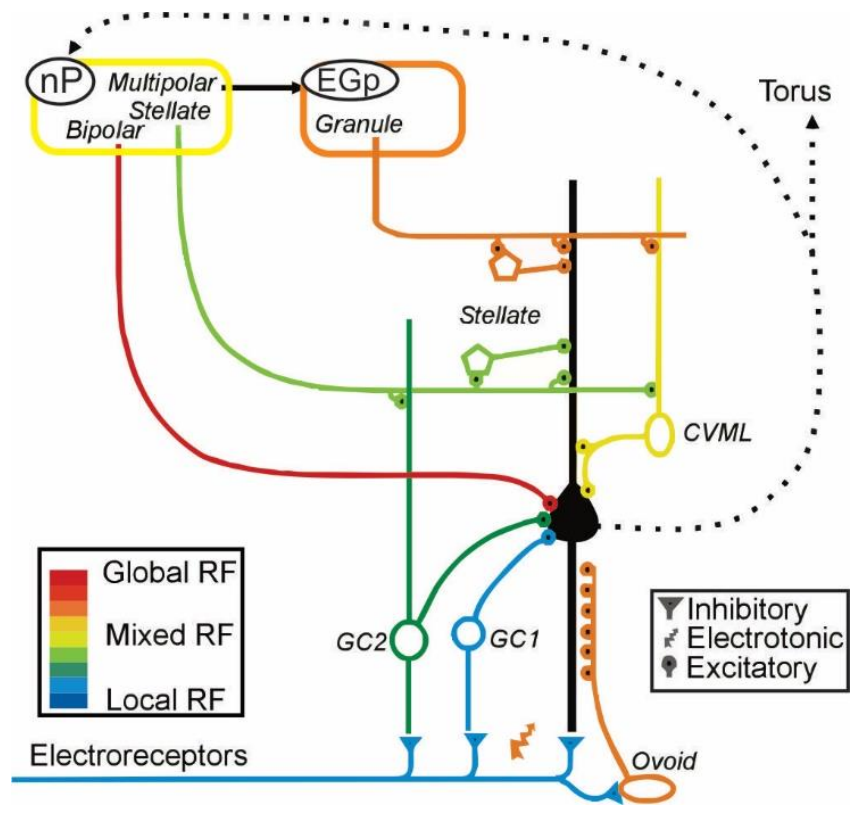

Figure 5. Circuitry of the ELL and immediate projections.

Each electroreceptor provides sensory input to the electrosensory lateral line lobe (ELL). Within the ELL, initial input is received by granule cells (GC1 and GC2), ovoid cells, and pyramidal cells (black hub). Pyramidal cells are the sole output neurons of the ELL, sending sensory information to the midbrain Torus semicircularis. A major source of input to ELL pyramidal cells comes from feedback pathways through the nucleus praeminentialis (nP) and the caudal lobe of the cerebellum (EGp). Stellate cells of the nP regulate the local direct feedback pathway (green) and form the basis of the "sensory searchlight" hypothesis. Bipolar cells of the nP provide global direct feedback, however the role of bipolar cells and global direct feedback has not been extensively studied. An indirect feedback pathway from the nP travels through the EGp and influences pyramidal cell activity. 
Spatial Processing in the Electrosensory System

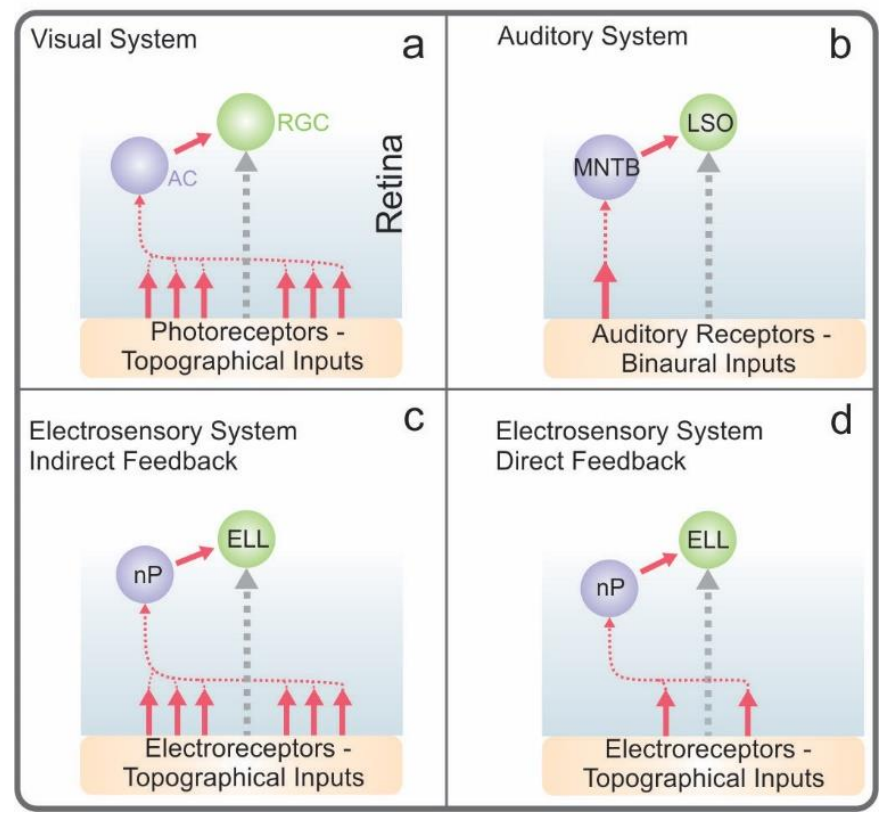

Figure 6. Shared network elements and potential feedback mechanisms contributing to localization and spatial processing.

In all panels, gray arrows represent feedforward input and red arrows represent feedback input. In the visual system (a), photoreceptors convey topographically organized visual input to retinal ganglion cells (RGCs) through additional layers of retinal circuitry. Most notably, amacrine cells (AC) influence RGC output and contribute to mechanisms such as background-suppression. A simplified depiction of sound localization in the mammalian auditory system is shown in panel (b). Binaural input from the ipsilateral side is sent to the lateral superior olive (LSO), while sensory input from the contralateral side is sent to the LSO by way of the medial nucleus of the trapezoid body (MNTB). Direct excitatory input to the LSO and indirect inhibitory input illustrate an early mechanism of spatial processing in the auditory system. Panels (c) and (d) show how electroreceptors provide topographical input to the ELL through a feedforward pathway, while the nucleus praeminentialis (nP) provides two forms of feedback input onto the ELL, an indirect feedback (c) and a direct feedback (d). Compared to the visual and auditory systems described above, different modes of feedback in the electrosensory system house shared network elements and are potentially involved in localization and spatial processing. 